\title{
XVII.
}

Aus der psychiatrischen und Nervenklinik in Kiel (Geh. Med.-Rath Prof. Dr. Siemerling).

\section{Beiträge zur pathologischen Anatomie der Katatonie.}

Von

\section{Dr. Renkichi Moriyasu}

aus Japan.

(Hierzu 3 Abbildungen im Text.)

Die Krankheit Katatonie ist vor mehr als 30 Jahren zuerst von Kahlbaum beschrieben worden, doch hat er damit anfangs wenig Anhänger gefunden. Später hat Kraepelin Kahlbaum's Lehren weitergeführt, die Katatonie aber nicht als selbstständige Krankheit beibehalten, sondern in dem grösseren Begriff Dementia praecox aufgehen lassen.

Wir halten ebenso wie Thomsen ${ }^{1}$ an der Bezeichnung Katatonie fest, da durchaus nicht immer eine Demenz sich entwickelt. Bei der zur Zeit herrschenden Uneinigkeit in der Nomenclatur wird es aber zweckmässig sein, die ganze über anatomische Befunde bei Dementia praecox und Katatonie vorhandene Litteratur zu berïcksichtigen.

Was die pathologische Anatomie sowohl der Katatonie wie der Dementia praecox betrift, sind die Ansichten der Autoren sehr mannigfaltig. Die Veränderungen, welche bis jetzt hervorgehoben worden sind, finden sich meist auch bei anderen Psychosen, z. B. Paralyse, Epilepsie, Dementia senilis $u$. s. w. und haben keine charakteristische Bedeutung.

Die einschlägigen Arbeiten sind überbaupt nicht zahlreich, sie sollen hier kurz zusammengestellt werden:

KlippeI und Lhermitte haben von vier typischen Fällen von Dementia praecox nach dem Tod eine genaue histologische Untersuchung der Hirnsubstanz vorgenommen. Makroskopisch fanden sie einestheils

1) Thomsen, Dementia praecox und manisch-depress. Irresein. Zeitschr. f. Psych. 64. S, 653. 
auf das ganze Gehirn, theils auf einzelne Lappen sich erstreckende Atrophie der Windungen, in einem Fall eine deutliche Asymmetrie des Kleinhirns. Mikroskopisch zeigten sich in allen Fällen eine Verkleinerung und Abrundung der Pyramidenzellen und eine Pigmentanbäufung einiger Neurogliazellen. Ganz besonders fielen den Autoren in Stirnlappen oder längs der Gefässe angehäufte Zellen auf, deren Kern sich mit basischen Farben stark färbten, während der Protoplasmaleib unsichtbar blieb. Klippel fand in vier anderen Fällen von Dementia praecox keine Veräuderungen des vasculären Bindegewebes, sondern einzig und allein Veränderungen im Neuroepithel. Er tritt der Ansicht Deny's entgegen, dass Unterschiede zwischen der Dementia praecox und den anderen Formen von Demenz mit vasculären Bindegewebsveränderungen nicht zu machen seien.

Mondio hat bei der anatomischen Untersuchung des Gehirns von Dementia praecox Asymmetrien in der Gestaltung der Windungen und der Formation beschrieben. Vikroskopisch fand er sehr starke Veränderungen der Ganglienzellen, und zwar gerade solche, wie sie von anderen Autoren bei den verschiedensten Vergiftungen und bei Idiotien beobachtet worden sind. Er hat betont, dass diese Vielseitigkeit der Veränderungen sehr gegen die Verwerthbarkeit der erbobenen Befunde spreche.

Obregia hat bei 7 Fällen von Dementia praecox histologische Befunde beschrieben. Im ersten Fall fanden sich viererlei Veränderungen. 1. Corticale Gebiete, in denen die nervösen Elemente ganz oder fast ganz fehlten. 2. Zonen mit Nervenzellen von grösserem Umfang und rumdlicher Form im Zustand der Chromatolyse. 3. Meningitische Veränderungen mit Verdickung und Zellproliferation. 4. Zellproliferation der Gefässadventitia. In zwei Fällen waren die Veränderungen weniger ausgeprägt und nur auf die Zellen bescbränkt. Es findet sich hier allein eine Veränderung der Trabantzellen. Die Gefüsse sind normal. Denselben Befund ergaben die Fälle 3-7. Bei den Fällen mit unversebrten Gefässen trat oft ein cytolytischer Process in den Vordergrund, der mehr oder weniger die Neurone in ihren Grundbestandtheilen ergriff, also Kern, Neurofibrillen, Chromoplasma.

Zalplachita fand bei histologischen Untersuchungen von Dementia praecox pathologische Veränderungen an allen Bestandtheilen der Hirnrinde; Zerstörungen an den Nervenzellen, Vermehrung der Neuroglia; Veränderung und Zerstörung der Gefässe. Die Elemente der Hirnrinde waren aber nicht gleichmässig ergriffen, sondern besonders stark in der tiefsten Schicht der grossen Pyramidenzellen, den Beetz'schen Zellen und polymorphen Zellen. Es handelte sich um chronische Nissl'sche 
Veränderungen mit Atrophien dieser Zellen. Daneben sah man üppige Vermehrung der Neurogliaelemente, besonders der Satelliten, die den Eindruck der Neurophagie erweckten und derjenigen Neurogliaelemente, die längs den Gefässen lagen. Bisweilen fanden sich auch in der Hirnrinde Gruppen solcher Elemente, die sogenannte Zellrasen bildeten. Die meisten Neurogliafasern waren gut entwickelt mit gut siehtbarem Kern versehen, doch fanden sich auch Zeichen von Rückbildung in Gestalt eines deformirten Kerns und von Pigmentgranulationen im Protoplasmakörper. Topographisch waren die Veränderungen am stärksten in den Frontallappen.

Klippel und Lhermitte haben auch bei der Dementia praecox in den Zellen der Vorderhörner des Rückenmarkes Atrophie, körnigen Zustand mit Pigmentirung des Zellprotoplasma beschrieben. Ausserdem haben sie betont eine ausgesprochene Entartung an den hinteren Wurzeln der Lumbalregion mit vollständiger Zerstörung der Achsencylinder. In den Hintersträngen derselben Gegend waren die mittleren Gefässzonen ausgesprochen sklerotisch. Stellenweise war der. Goll'sche Strang lädirt. Im corticalen Theil war nur der innere Theil dieses Stranges erkrankt. In den erkrankten Parthien fand man Proliferation der Neuroglia und Lücken, wo gleichzeitig die Achsencylinder und die Neuroglia fehlten.

Eisath-Hall hat ebenfalls über Gliaveränderungen bei Dementia praecox gearbeitet. Er fand in der molecularen Randzone Dunkelfärbung der Kerne and Vermehrung der Weigertfasern, letzteres, wenn nicht allenthalben, so doch stellenweise. In der Meinert'schen Schichte der Rinde waren die protoplasmatischen Fasern in allen Fällen verwachsen, undeutlich und in verminderter $\mathrm{Zahl}$ sichtbar, dagegen in 3 Fällen vermelurte Weigertfasern über die ganze Rinde ausgebreitet Die. runden Gliaelemente wiesen in 3 Fällen vermehrte Gliakernchensubstanz auf. In allen Fällen waren sichelförmige Trabantzellen zu sehen, manchmal jedoch ausserordentlich spärlich, pigmentöser Zerfall der Begleitzellen in allen 7 . Beobachtungen.

Vogt hat in vier Fällen von Katatonie histologische Befunde beschrieben.

Im ersten Falle zeigten die Nervenzellen normale Structur. Die Neurogliakerne waren durchgehends gross, von grossem, deutlich sichtbarem Zellleib umgeben. Recht viel gelbes Pigment lag in den Zellen. Im Mark fanden sich noch einige kleine, eckige Kerne. Die Gefässe hatten nur vereinzelte Kerne in der Adventitia.

Im zweiten Fall zeigten die Nervenzellen starke chronische Veränderungen. Die Glia bot deutliche Kernvermehrung. Die Kerne waren 
mittelgross, rund, häufig von grossen spinnenförmigen Zellleibern umgeben. In der zellarmen Zone bildeten die Ausläufer der Spinnenzellen ein sichtbares maschenförmiges Netz. Die Gefässwand war reich an Intima- und Mediakernen. In den häufig etwas ausgebuchteten Adventitiascheiden lagen einige kleine Lymphocyten. Viel Pigment in der Gefässwand.

Beim dritten Fall boten die Nervenzellen chronische Veränderungen.

Die Glia liess in der zellarmen Zone leichte Vermehrung von Zellen erkennen, die deutliche Spinnenform zeigten. In der Rinde waren grosse Gliakerne mit grossen Kernkörpercben, die Zellleiber deutlich.

An den Gefässen war die Adventitia zellarm, und selten fanden sich einige blaue langgestreckte Kerne, die an beiden Polen von einem hellen, kleinen Protoplasmasaum umgeben waren. Zum Theil Anliäufung von Gliakernen an den Gefässwänden.

Beim vierten Fall hatten die Nervenzellen chronische Veränderungen erlitten. An der Glia bestand in dem äusseren Theil der zellarmen Zone erhebliche Vermelirung von stark geschrumpften spinnenförmigen Zellen. Sonst kleine Zellvermehrung, die Kerne waren von mittlerer Grösse, hell, in den recht deutlichen Zellleibern viel gelbes Pigment. Die Gefässwände zum Theil etwas dick, sonst von guter Structur.

Alzheimer hat bei wahrseheinlichen Katatoniefällen Neubildung: von Gliafasern, Umklammerung der Ganglienzellen auf die tieferen Rindenschichten beschränkt beschrieben.

Maschtschenko fand bei Dementia secundaria beträchtliche Verminderung der Anzahl der Nervenzellen, besonders der kleinen Pyramiden, ausgebreiteten Schwund der Associationsfasern in der Hirnrinde und sklerotische oder atheromatöse, zum Theil obliterirende Gefässe.

Dreyfus hat in einem Fall von Tod im katatonischen Anfall bei alter Dementia praecox die histologische Untersucbung gemacht. Dieselbe beschränkte sich auf die Grosshirnrinde und das Rückenmark. Es liess sich nichts Positives feststellen.

Die Anordnung der Ganglienzellen war gut erhalten. Die Ganglienzellen selber zeigten im Allgemeinen keine erhebliche Veränderung. Die Gefässe waren etwas blutreich, ihre Wandungen nicht verdickt. Die adventitiellen Lymphscheiden waren nicht erweitert, enthielten keine zelligen Elemente, speciell fanden sich nirgends Plasmazellen. Die Pia war völlig normal, nur waren ihre Blutgefässe ziemlich stark gefüllt.

Das Rückenmark wurde nach Weigert-Pal gefärbt. Es liess sich 
nirgends Degeneration nachweisen, insbesondere waren die Hinterstränge völlig intact.

Cramer hat bei typischem Fall mit 6 jähriger Krankheitsdauer histologische Befunde beschrieben. Die Gefässwände waren nicht sehr kernreich, zeigten auch in ihrer adventitiellen Scheide nur wenig Kerne. In einzelnen Gefässen der Rinde, besonders der tieferen Schichte, fanden sich im adventitiellen Raum einzelne grössere, blass tingirte Kerne, die in ihrem Aussehen vollständig Gliakernen glichen. In der Markleiste fanden sich vereinzelte Gefässe, welche entschieden verdickte Wandungen hatten, stellenweise mit Leukocytenkernen besetzt waren und auch, wenn auch sehr selten, im adventitiellen Raum kleine Häufchen extracellulär liegenden Pigments erkennen liessen. Die Ganglienzellen erschienen im Allgemeinen kleiner als normal und stark tingirt. Die Nisslkörper waren stark zerstört, der Kern häufig an die Peripherie gerückt, auch standen fleckweise die Zellen nicht so schön ausgerichtet als unter normalen Verhältnissen. Die Glia war stark gewuchert, besonders in den tieferen Schichten der Hirnrinde und in der Umgebung der Gefässe.

Denselben Befund an Glia, Zellen und Gefässen hat Cramer dann auch in einem anderen Fall von Jugendirrsein, der unter dem Hervortreten katatonischer Erscheinungen zur Verblödung führte, erhoben. In diesem Fall hat er auch das Verhalten der markhaltigen Fasern studirt und einen zwar nicht sehr ausgedehnten, aber deutlich markirten Faserschwund gefunden.

So weit ich also die Litteratur nachgesehen habe, sind die Be. funde der Autoren vielseitig und ergeben nichts Bestimmtes. Ich möchte nun zunächst über meine eigenen histologischen. Befunde an Grosshirnrinde und Rückenmark bei Anwendung verschiedener Methoden berichten. Krankengeschichten und Sectionsbefunde werden der Vollständigkeit halber ziemlich ausführlich mitgetheilt:

\section{Fa11 1.}

D. S. 31 Jahre, Schneiderin, wurde am 25. März 1905 aufgenommen; am 10. April gestorben.

Heredität negirt. Menses regelmässig. Hat mit 15 Jahren im Krankenhaus gelegen, wurde operirt am linken Fuss und an den Rippen. Vor 2 Jahren bereits psychisch erkranlit. Habe allerhand gesehen. Aeusserte, die Eltern wollten sie umbringen, ihr Bruder sei an der Krankbeit schuld. Nach 2 bis 3 Tagen ging dieser Zustand vorüber. Hat in der Schule gut gelernt. War auch als Kindermädchen in Stellung, gab die Stellung auf, weil sie krank wurde, war nachher zu Hause. Seit 3 Jahren als Schneiderin thätig. Soll immer sehr rubig gewesen sein, machte sich nichts aus Vergnügungen. Vor 6 Jabren erkrankte Patientin plötzlich, gab an, sie habe Magenschmerzen. Lag 
im Bett. Lärmte, wollte nicht ruhig liegen bleiben, kramte im Zimmer umher. Redete wirres Zeug, wollte keine Medicin einnehmen, sie würde dadurch nur noch kränler. Wusch sich heute den ganzen Tag. Kühlte sich den Kopf und weinte viel. Keine Sinnestäuschungen. Hat die letzten 5 T'age keinen Schlaf gehabt. Gegessen hatie sie gut. Keine Krämpfe.

Status, graciles Mädchen. Schädel und Wirbelsäule nicht druckempfindlich. Pupillen mittelweit, gleichrund.

R/L. + R/C. + A. B. frei. VII frei.

Zunge gerade, belegt. Gaumen und Rachen ohne Besonderheit. Lungen und Herz frei. Puls 100, regelmässig. Am Thorax zahlreiche, umfangreiche Narben und Knochendefecte. Alle Narben mit der Unterlage verwachsen, nicht druckempfindlich. An dem Fussgelenk mehrere Narben, das Gelenk selbst ist steif. Kniereflexe lebhaft. Achillessehnenreflexe links + , rechts Null (steifes Gelenk). Plantarreflexe †. Sensibilität am ganzen Körper intact nur an den Narben Schmerzempfindlichleit berabgesetzt. Motilität ist frei bis auf das rechte Fussgelenk, das unbeweglich. Beim Gehen tritt Patientin rechts nur mit der Fussspitze auf.

26. März. Hat in der Nacht ruhig geschlafen, war oft aus dem Bette, ging an das Bett einer anderen Patientin, glaubte, es sei ihre Mutter, schrie laut auf. Hat eingenässt und sich beschmutzt. Sagte, sie habe Angst gehabt, man wolle sie todt machen.

27. März. Ist sehr unruhig. Schreit laut auf, lässt sich auch auf Zureden nicht beruhigen. Nach dem Dauerbad etwas ruhiger. Schläft etwas, nach dem Erwachen stösst Patientin wieder fortwährend laute bellende Schreie aus. Zeigt dabei ängstlichen Affect.

30. März. Zeigte in den letzten Tagen grosse Unruhe. Schreit und läuft im Saal umher. Zuweilen kriecht sie am Boden umher und ist nicht zum Gehen zu veranlassen. Wehrt sich heftig, wenn man sie anfasst. Macht grosse Schwierigkeiten bei der Nahrungsaufnahme. Ist auch in der Nacht meist sehr laut, auf Schlafmittel reagirt sie nur mit wenig ausgiebigem Schlaf.

31. März. Nachts unruhig, schmutzig, ass Koth. Heute wieder sehr laut. Mit Mühe im Bade zu halten.

1. April. Wenig geschlafen, war aber ruhig. Auch tagsüber liegt Patientin ruhig, völlig theilnabmslos zu Bett. Stöhnt mit leerem Gesichtsausdruck vor sich hin, Dauerbad. Verweigert Nahrung, Sondenfütterung.

4. April. Wenig geschlafen, war aber ruhig. Auch tagsüber liegt $\mathrm{Pa}$ tientin ruhig, völlig theilnahmslos zu Bett, stöhnt mit leerem Gesichtsausdruck vor sich hin, spricht nicht. Nimmt die Nahrung, die ihr mit dem Löffel gereicht wird. Erysipel der rechten Glutaealgegend.

5. April. Nachts sehr unrubig, wühlte im Bettzeng umber, verbigerirte. Unsauber. Tagsüber sehr unruhig, wirft die Bettlaken aus dem Bett, schreit viel und verbigerirt. Erysipel ist auch auf die linke Glutaealgegend übergegangen.

7. April. Nachts nach 8 Par. gut geschIafen. Sonst unverändert. Erysipel schreitet auf der Aussenseite des rechten Obersehenkels fort. 
8. April. Auf 8 Par. gut geschlafen. Tagsüber unruhig, verbigerirt, versucht beständig aus dem Kastenbett zu klettern, zieht die Wäsche aus, wühlt im Bettzeug. Nimmt ziemlich reichlich flüssige Nahrung, sieht sehr abgefallen aus. Hat kleinen schwachen Puls.

8. April. Nachts gut geschlafen. Jammert und stöhnt beständig vor sich hin, zerwühit das Haar. Nimmt nichts zu sich, spuckt alles wieder aus, sieht sehr abgefallen aus. Puls klein, kaum zu fühlen, 120 in der Minute. Athmung sehr gesteigert, 40 in der Minute. Ueber den unteren Partien beider Lungen Rasselgeräusche, keine deutliche Dämpfung, Untersuchung durch das heftige Widerstreben sehr erschwert. Kampferinjection.

10. April. Nachts 1 Uhr Exitus letalis.

Section: Gehirngewicht 1206. Schädeldach nicht verdickt, Dura mit dem Sohädeldach ziemlicb fest verwachsen. Pia mässig verdickt, lässt sich in Fetzen abziehen, nicht getrübt, an anderen Stellen durch Flüssigkeitsansammlung abgehoben. Venen und Sinus stark gefüllt. Gefässe nicht verdickt. Rückenmark obne Besonderheit. Dunkelrothbraune Färbung der Haut über dem linken Glutaeus. Ziemlich weiche Milz mit geschrumpfter Kapsel. Hyperämische Lungen mit Hypostase in den Unterlappen, pleuritische Adhäsion beiderseits, besonders rechts. Trübes Herz. Geringe fettige Fleckung der Aortaklappen. Schnürfurche der Leber. Stark ectatischer Magen mit geringer strahliger Narbe und ausheilendem Geschwür daneben an der kleinen Curvatur. Granularatrophie der Nieren, besonders rechts. Stark contrahirte Blase mit kleinen Hämorrhagien der Schleimhaut. Hyperämischer Darm. Alte Narben am linken Fuss, linker Hand. Resection von Theilen der 5. und 6. Rippe.

\section{Mikroskopische Untersuchung.}

Grosshirnrinde.

Mit Toluidinblaufärbung: 3. Stirnwindung. Das Präparat ist im Ganzen mehr blass gefärbt. Die Veränderungen der Ganglienzellen sind nicht bedeutend. Stellenweise sieht man, dass die Ganglienzellen angeschwollen sind mit Zerfall der Granula im Zellleib, und dass der Kern blasig und an die Peripherie gedrückt ist. In der Umgebung der Gefässe finden sich bald einfache Reihen bald mehr gehäuft Rundzellen. Manchmal findet man auch diese Zellen vereinzelt in der Gefässwand. Hier und da findet man in der Gefässwand viel Pjgment und vereinzelte Mastzellen. Die Gefässe sind meist mit Blut gefüllt, besonders in den Markleisten. Die Capillaren haben sich etwas vermehrt. Trabantzellen sind nicht viel vermehrt, sondern nur hier und da um die Ganglienzellen gelagert.

Nach Weigert und Pal. Die Markfasern, welche in der Tangentialschicht sich finden, sind nicht erheblich gelichtet, aber sie sind stellenweise mehr aufgequollen, als normal und ibr Verlauf erscheint nnregelmässig. Die supraradiären Fasern, welche schräg, quer und unregelmässig verlaufen, sind ziemlich stark vermindert. Die radiären Fasern sind stellenweise dünn. 
Die Capillaren sind strotzend gefüllt. Die Gefässe, welche in den Markleisten sich finden, zeigen in den perivasculären Räumen ziemlich starke rundzellige Anhäufung.

Mit Toluidinblaufärbung: Vordere Centralwindung: Einige Beetz'sche Riesenzellen zeigen homogene Schwellung. Die Veränderungen der Ganglienzellen und der Gefässe sind wie in der Stirnwindung. Aber die Trabantzellen-Vermehrung um die Ganglienzellen und die Rundzellen-Anlagerung an die Gefässe ist hier deutlicher als in den Stirnlappen.

Nach Weigert und Pal. Die Tangentialfasern sind etwas vermindert. und viel mehr aufgequollen als normal. Stellenweise sind die radiären Fasern auch stark angeschwollen.

Nach Bielschowsky. In der ersten und zweiten Schicht sind die extracellulären Fibrilien meist in kleine Stücle zerfallen und stark vermindert. Die Ganglienzellen, besonders die kleinen und grossen Yyramidenzellen, haben im Ganzen eine gut erhaltene äussere Form, und die Spitzenfortsätze sind auf weitere Strecken rerfolgbar, aber der Zellleib, besonders der Kern, hat sich intensiv schwarz gefärbt.

Stellenweise kann man constatiren, dass die grossen Pyramidenzellen, deren Zellleib sich umgestaltet und sich mit schwarzer Masse gefüllt hat, deren Kern stark schwarz gefärbt ist, keine Fortsätze besitzen.

Zwischen den veränderten Ganglienzellen sieht man auch normale Zellen. In der tieferen Schicht sind die Ganglienzellen (multiforme und spindelförmige Zellen) relativ gut erhalten.

Nach van Gieson. Stark gelichtet und stellenweise in kleine Stücke wie Staub zerfallen. Die Ganglienzellen haben im Allgemeinen die Fortsätze verloren, sich umgestaltet und schwarz gefärbt, besonders der Kern. Im Zellleib findet man eine schwarzkörnige Masse. Der zellige Aufbau der Rinde ist verwaschen, besonders sind die Veränderungen in den Pyramidenzellen stärker.

Die Beetz'schen Riesenzellen zeigen im Zellleib durch Verkleben der Fibrillen Lichtungen, welche manchmal bei weiterem Zerfall der Fibrillen zu circumscripten unregelmässigen Löchern sich ausbilden. $A b$ und zu haben die Ganglienzellen stumpfe Spitzenfortsätze, in denen die Fibrillen relativ gut elhalten oder zu dicken Fasern sich verklebt haben. Es giebt aber stellenweise auch wieder ganz normale Ganglienzellen.

Nach ran Gieson. Wie in der 3. Stirnwindung.

Mit Toluidinblaufärbung. Hintere Centralwindung. Die Veränderungen der Ganglienzellen sind fast wie in der vorderen Centralwindung, die Gefässe haben bis zu den Capillaren hinab sich strotzend gefüllt. Um die Gefässe haben sich Rundzellen ziemlich stark angehäuft. Die Gefässe sind vermehrt.

Nach Weigert-Pal. Die Tangentialfasern sind stellenweise in kleine Stïcke zerfallen und haben stark abgenommen. Stellenweise sind sie gut erhalten. In der 2. und 3. Schicht sind die Fasern (supraradiäre und interradiäre Fasern) stellenweise stark gelichtet; die radiären Fasern auch. 
Nach Bielschowsky. Die extracellulären Fasern in der 1. Schicht sind im Ganzen in Bruchstücke zerfallen, stark gelichtet, stellenweise total verschwunden. In der 2. und 3. Schicht haben sie auch stark abgenommen. Die kleinen Pyramidenzellen haben sich stark verändert. Der Kern ist intensir schwarz gefärbt und die Fibrillen des Zellleibes sind stark zerfallen. Die grossen Pyramidenzellen zeigen stellenweise ein. Verbacken der Fibrillen, stellenweise durch Zerfall derselben helle Stellen. Man sieht anch stark angeschwollene Spitzenfortsätze, deren Fibrillen sich miteinander verklebt haben.

Nach van Gieson. Wie in 2. Stirnwindung.

Mit Toluidinblaufärbung. Fissura calcarina: Die Ganglienzellen sind meist gut erhalten, stellenweise haben die Meynert'schen Solitärzellen sich blasser gefärbt; und die Granulation im Zellleib ist in feine Massen zerfallen, ihr Kern ist verschwanden.

Die Veränderungen der Gefässe wie in der hinteren Centralwindung.

Nach Weigert-Pal. Die Tangentialfasern sind mittelstarik vermindert. Die Fasern in der 2. bis 3. Schicht sind in kleine Stücke zerfallen, etwas vermindert. Die radiären Fasern sind stellenweise gelichtet.

Nach Bielschowsky. Die extracellulären Fibrillen sind in der 1. bis 2. Sohicht stellenweise in lörnige Massen zerfallen und stark vermindert. Die kleinen Pyramidenzellen zeigen gut erhaltene äussere Form und langverfolgbaren Spitzenfortsatz, aber der Kern ist stark schwarz gefärbt. In den grossen Pyramidenzellen sind die Fibrillen des Zellleibes zerfallen und die Zellen zeigen kleine hello Stellen.

Nach van Gieson. Stellenweise sind die Capillaren rerdickt und zeigen mässige Anhäufung der Rondzellen um die Gefässe.

\section{Rückenmark.}

Mit Toluidinblaufärbung. Halsmark: stellenweise zeigen die Pyramidenzellen der Vorderhörner Chromatolyse, und der Kern ist an die Peripherie gerückt.

Es giebt auch Pyramidenzellen, welche homogen dunkelblau gefärbt sind und deren Fortsätze auf weitere Strecken verfolgbar bleiben. Im Allgemeinen sind die Pyramidenzellen gut erhalten. Im Grundgewebe sind die Rundzellen (Gliakerne) vermebrt. Man sieht auch Anhäufung der Rundzellen um die Ganglienzellen, welche sich sehr blass gefärbt haben und zum Teil zerfallen sind.

Die Gefässe haben sieh meist mit Blut gefüllt, dieCapillaren sind stellenweise verdickt.

Nach van Gieson. Die Glia ist in den Hintersträngen, besonders in der Peripherie der Burdach'schen Stränge und in den peripheren hinteren Theilen der Seitenstränge inselförmig vermehrt. Die Gefässe sind mit Blut stark gefüllt. Hier und da liegen Corporaamylacea.

Nach Weigert-Pal. In der Peripherie des Goll'schen und des Seitenstrangs sind die Markfasern etwas gelichtet. Sonst keine Veränderung. 
Nacb Marchi. In allen Strängen findet man diffus wenige schwarze Punkte.

Mit Toluidinblaufärbung: Brustmark. Die Ganglienzellen in den Clarke'sohen Säulen sind im Ganzen verändert. Im Centrum des Zellleibes sind Nisslkörper fein zerfallen oder ganz verschwunden, sodass die entsprechende Stelle einen hellen Fleck darstellt. In der Peripherie finden sich als spärlicher Saum kleine zerfallene Granula. Der Kern ist blasig angeschwollen und an die Peripherie gerückt, manchmal ist er ganz versebwunden. Der Zellleib ist meist in toto angeschwollen. Im Vorderhorn sieht man Ganglienzellen, welche intensir blau gefärbt sind, deren Kern ganz verloren ist, deren Fortsätze sich geschlängelt haben. Uebrige Veränderungen wie im Halsmarke.

Nach van Gieson. Die Capillaren sind stark gefüllt. Gliavermehrung nioht deutlich.

$\mathrm{Nach}$ Weigert. Die Markfasern sind in derPeripherie der Seitenstränge und der Hinterstränge etwas gelichtet. Die Markfasern, welche aus den hinteren Wurzein in die Clarke'schen Säulen einstrahlen, scheinen auf der einen Seite weniger geworden als auf der anderen.

$\mathrm{Nach}$ Marchi. Wie im Halsmark.

Nach Toluidiablaufärbung. Lendenmark: Die Ganglienzellen in den Clarke'schen Säulen zeigen centrale Chromatolyse ebenso in den Vorderhörnern. Die Anzahl der Zellen ist in den Clarke'schen Säulen stark vermindert.

Nach van Gieson. Man bemerkt Gliawucherung in den Seitensträngen. Die Gefässe sind sehr gefüllt. Hier und da Amyloidliörperohen.

Nach Weigert. Die Marlfasern sind in der Peripherie der Hinterstränge und Seitenstränge etwas gelichtet.

Nach Marchi. Wie im Halsmark.

\section{Fall ?.}

D. L., 44 Jahre, Wittwe, wurde am $\tau$. November 1906 aufgenommen, am 13. November gestorben.

Wird zur Abtheilung getragen, widerstrebt sehr. Sitzt mit stark nach vorn übergebeugtem Oberkörper im Untersuchungszimmer, stieren Blicks, mit dem Oberkörper hin und her schwanliend. Murmelt unverständlich vor sich hin. Befolgt A ufforderungen nicht. Bezeichnet dann vorgehaltene Gegenstände richtig. Beantwortet einzeine Fragen, dann wieder unverständliches MurmeIn. Körperliche Untersuchung durch Widerstreben sebr erschwert.

Status: Kräftiger Knochenbau, geringe schlaffe Muslrulatar. Dürftiger Ernährungszustand. Beim Blick geradeaus andauernd nystagmusartige Zuckungen. Pupillen mittelweit, gleich. $\mathrm{R} / \mathrm{L}+\mathrm{R} / \mathrm{C}+\mathrm{A} \mathrm{B}$ nicht zu pröfen. VII $r>1$. Aufgefordert, die Zunge herauszustrecken, schneidet sie Grimasscn, steckt dann die Zungenspitze ganz nach rechts aus dem Mund heraus. Leichter Tremor. Keine Motilitätsstörungen. Gelenke frei. Reflexe der o. E. + 十. Mechanische Muskelerregbarkeit etwas erböht. Leichtes vasomotorisehes 
Nachröthen. Abdominalreflexe, Patellarreflexe +-+ . Zehen plantar. Gang unsicher, ganz nach vorn übergebeugt. Schmerzempfindung anscheinend etwas herabgesetzt. Lungen o. B. Herztöne rein. Puls 80, regelmässig. Abdomen aufgetrieben, lauter tympanischerSchall. Legt sich im Bett ganz an den Rand, lässt den Kopf heraushängen, droht hinauszufallen.

10. November 1906. Temperatur 37,90. Liegt ruhig, spricht nicht, murmelt unverständlich vor sich hin. Schreit oft laut auf. Urin mit Katheter entleert. Menge 1000. Spec. Gew. 1029, ohne Eiweiss und Zucker. Abendtemperatur $38,7^{\circ}$. Drohender Handteller-grosser Decubitus.

11. November. Temperatur $38,8^{\circ}$. Ueber beiden Lungen rauhes Athmen. Durchfall. Lässt sich nur schwer untersuchen. Sehr widerstrebend: $2 \mathrm{mal}$ täglich Sondenfütterung.

12. November. Verfallenes Aussehen, kleiner, kaum fühlbarer Puls, 124. Temperatur 38,90 . Durchfall. Urin angehalten.

13. November. Morgens zwischen 4 und 6 Ohr Exitus.

Section: Magere Leiche. Aeusserst geringes Fettpolster. Pleuren bindegewebig verwachsen, besonders rechts Pleuraschwarten. Leichtes Emphysem. Hypostase des rechten Unterlappens. Herz von normaler Grösse. Linker Ventrikel contrahirt. Herz schlaff, Klappen zart. Kurze Sehnenfäden an der Tricuspidalis. Trachea enthält Schleim. Leber fettreich. Im Magen eine Narbe mit starker Narbencontraction. Aus der Narbe wächst ein erbsengrosser Schleimhautpolyp heraus. Ausserdem noch mehrere bis haselnussgrosse Polypen in der Magenschleimhaut, die darïber intakte Magenschleimhaut aufgelockert, verdickt. Leichter Katarrh des Dickdarmes. Milz etwas derb. Nieren ohne Besonderheit. Alte Verwachsungen im Paranetrium; das Colon transversum wird durch dieselben nach hinten unten winklig abgebogen. Schädel mässig dick und schwer. Dura glatt. Längssinus enthält wenig flüssiges Blut. Pia leicht verdickt. Narben und Gefässe frei. Hirngewicht $1315 \mathrm{~g}$.

\section{Grosshirnrinde.}

Mit Toluidinblaufärbung. 3. Stirnwindung: Die Ganglienzellen in der tiefen Sehicht (4-5) sind angeschwollen; der Kern ist an die Peripherie gerückt und die Nisslkörper zerfallen. Es giebt unter den grossen und kleinen Pyramidenzellen solche, welche blass oder sehr dunkelblau gefärbt und deutlich verschmälert sind, deren Kern längliche, schmale Form zeigt. Stellenweise bieten die Ganglienzellen, welche sehr blass gefärbt sind, in ihrem Zellleib mehrere Vacuolen dar, sodass sie manchmal wie aus Maschen zu bestehen. scheinen. Hier und da finden sich Stäbchenzellen. Die Gefässe sind bis zu den Capillaren hinaus mit Blut strotzend gefüllt. Stellenweise sind die Endothelkerne gewuchert. Auf den Gefässwänden findet man Pigment. Die Trabantzellen sind um die Ganglienzellen stark vermehrt.

Nach Weigert-Pal. Die Tangentialfasern sind stellenweise bedeutend vermindert, stellenweise ziemlich gut erhalten. In der 2.-3. Schicht sind die supra- und intraradiären Fasern im Allgemeinen mässig stark gelichtet. An den stark gelichteten Stellen haben die radiären Fasern anch abgenommen. 
Nach Bielschowsky. Die extracellulären Fibrillen sind in der 1. bis 3. Schicht ganz klein zerfallen und bedeutend rermindert, besonders in der 1. Schicht stellenweise total verschwunden. Die Ganglienzellen, besonders die Jileineren und mittelgrossen Pyramidenzellen haben gut erbaltene äussere Form; aber sie haben sich ganz schwarz gefärbt, besonders der Kern. Die Fibrillen des Zellleibes haben sich zu schwarzen Klumpen umgewandelt oder zu dicken Fasern verklebt. Selten sind die Pyramidenzellen gut erhalten. Es giebt Pyramidenzellen, welche im Zellleib ciroumscripte helle Stellen besitzen. Die Ganglienzellen in der tieferen Schicht sind relativ gut erhalten. Stellenweise sind die radiären Fibrillenzüge gelichtet.

Nach van Gieson. Capillaren stark gefüllt. Leichte Anhäufung von Rundzellen um die Gefässe.

Mit Toluidinblaufärbung. Vordere Centralwindung: Die grossen und kleinen Ganglienzellen enthalten viel Pigment. Die Pyramidenzellen haben überhaupt vor Allem Veränderungen erlitten. Sie haben sich sehr blass gefärbt, und ihre Kerne sind fast durchweg verschwunden. Die Nisslkörper sind fein zerfallen. Es giebt Ganglienzellen, welche mit fein zerfallenen Granula angefüllt sind, und derenan diePeripherie gerückter Kern ganz undeutlich ist, sodass nur das Kernkörperchen sich intensiv blau gefärbt abhebt. Hier und da finden sich Ganglienzellen, welche homogene Schwellong zeigeu. Trabantzellen sind um die Ganglienzellen stark angebäuft oder förmlich in ihren Leib eingedrungen. Die Gefässse sind mässig mit Blut gefüllt, in den Gefässwänden findet man Pigment. Leichte Infiltration um die $\mathrm{Ca}$ pillaren.

$\mathrm{Nach}$ Weigert-Pal. Die Tangentialfasern sind stellenweise in kleine Stüclie zerfallen und bedeutend vermindert. Stellenweise sind sie ziemlich gut erhalten und lang verfolgbar, doch meist perlschnurartig oder spindelförmig aufgequollen. In der 2.-3. Schicht haben die supraradiären und interradiären Fasern stellenweise abgenommen, die radiären Fasern sind hier und da gelichtet.

Mit Bielschowsky: Die Veränderungen wie im Stirnlappen. Nur ist der Kern der Pyramidenzellen mehr schwarz gefärbt. Die Fibrillen im Zellleib sind meist stark zerfallen und hier und da ganz verschwunden. Es giebt Ganglienzellen, welche im Zelleib grosse helle Stellen zeigen.

Naoh ran Gieson: Wie in der Stirnwindung.

Mit Toluidinblaufärbung: Hintere Centralwindung: Die Ganglienzellen, besonders die grossen Pyramidenzellen, zeigen stärkere Veränderungen. Der Kern ist an die Peripherie gerückt, der Zellleib diffus blau gefärbt oder sehr dunkel gefärbt. Die Nisslkörper sind in kleine Massen zerfallen. Es giebt Ganglienzellen, welche sich umgestaltet haben, um die Kerne ganz hell sind und nur in der Peripherie noch Granula regelmässig gereiht haben. Uebrige Veränderungen wie in der vorderen Centralwindung.

Nach Weigert-Pal: Stellenweise sind die Tangentialfasern, supraund interradiären Fasern mittelstark vermindert, stellenweise auch die radiären Fasern gelichtet. 


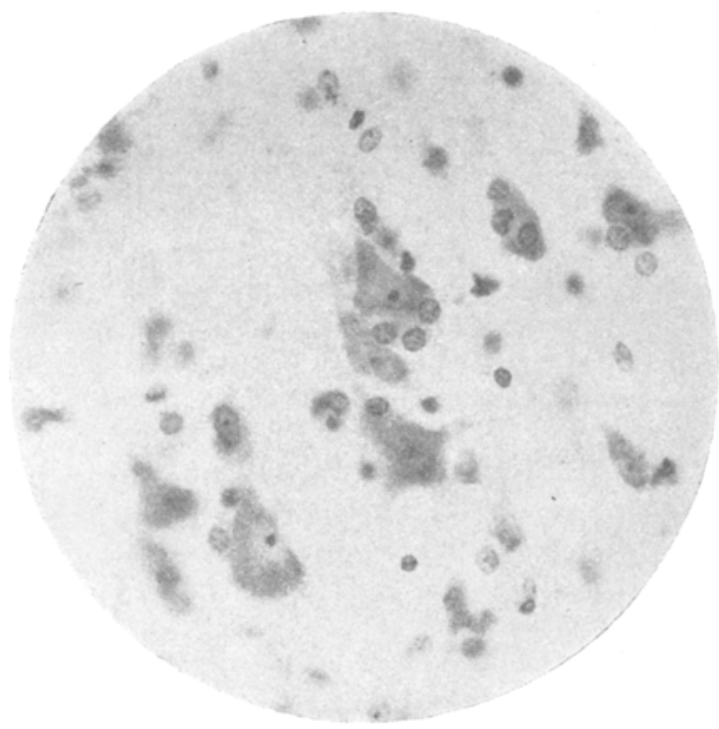

Abbildung I. Hirnrinde (vordere Centralwindung). Die Trabantzelien zeigten ju den periceliuläron Räumen starke Anhäufung und erschienen manchmal in dic Ganglienzellen eingedrungen, es haben die Ganglienzellen sich dementsprechend umgestaltet, so dass der Zellleib nach aussen concav erscheint.

Object. Zeiss E. Projectionsocular 2. Abstand $39 \mathrm{~cm}$.

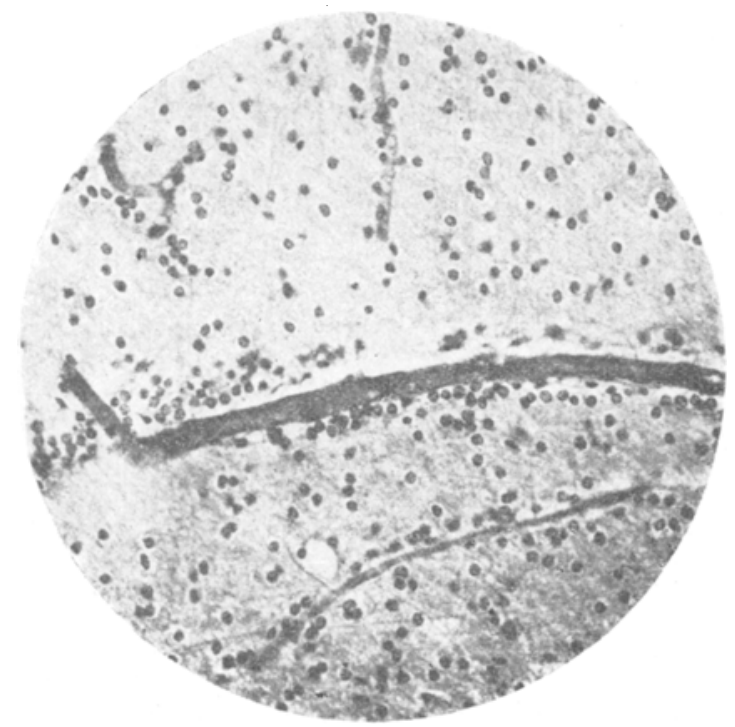

Abbildung Ir. Hirnrinde (hintere Centralwindung). Die Glidkerne haben sich streckenweise zu beiden Sejten um die Gefässe stark angehäuft.

Object. Zeiss 8. Projectionsocular 2. Abstand $36 \mathrm{em}$. 
Nach Bielschowsky: In der 1. - 2. Schicht haben die extracellulären Fasern bedeutend abgenommen, sind stellenweise total verschwunden. Die radiären Fasern sind auch gelichtet. Die Ganglienzellen haben meist gut erhaltene äussere Form und die Spitzenfortsätze sind auf weitere Strecken verfolgbar. Aber der Kern ist sehr schwarz gefärbt. Es giebt Ganglienzellen, deren Zellleib stark zerfallen ist. Stellenweise finden sich gut erhaltene Ganglienzellen, wie noimal.

Nach van Gieson: Die Gliakerne sind um die Gefässe stark angehäuft.

Mit Toluidinblaufärbung. Fissura calcarina: Stellenweise sind die Meynert'schen Solitärzellen stark angeschwollen, zeigen centrale Chromatolyse; der Kern ist in die Peripherie gerückt. Stellonweise sind die Ganglienzellen diffus blass oder dunkelblau gefärbt und ibre Spitzenfortsätze auf weitere Strecken verfolgbar. Die Capillaren sind vermindert und mit Blut stark gefüllt. Uebrige Veränderungen wie in der vorderen Centralwindung.

Nagh Weigert-Pal: Die Tangentialfasern sind stellenweise bedeutend vermindert, stellenweise in kleine Stücke zerfallen. Die supra- und interradiären Fasern sind auch bis in die tiefe Schicht stark vermindert. Die radiären Fasern sind stark zerfallen und haben nicht mehr die 3. Schicht erreicht. Stellenweise sind sie ganz vereinzelt vorhanden.

Nach Bielschowsky: Die Veränderungen wie in der hinteren Centralwindung. Die Solitärzellen haben im Zellleib circumscripte gelichtete Stellen.

Nach van Gieson: Veränderung wie in der hinteren Centralwindung.

Rückenmark.

Mit Toluidinblaufärbung. Ilalsmark: Die Ganglienzellen in Vorderhorn zeigen centrale Chromatolyse und homogene Schwellung. Es giebt Ganglienzellen, welche sich homogen blass verfärbt haben, in deren Basis bei mittelstarker Vergrösserung stecknadelknopfgrosse rundliche Vacuolen liegen und deren Kern excentrisch verschoben ist. Man findet auch Ganglienzellen, welche wie Schatten verfärbt sind und im Zellleib einige Vacuolen zeigen. Die Ependymzellen um den Centralcanal sind stark gewuchert.

Nach van Gieson: Die Glia ist im hinteren Theil der Seitenstränge gewuchert. Gefässe zeigen keine auffallende Veränderungen.

Nach Weigert-Pal: Die Marlfasern sind im peripheren Theil der Seitenstränge and in der Umgebung $d$. Sept. post. etwas gelichtet.

Nach Marchi: In allen Strängen liegen schwarze Punkte diffus zerstrent.

Mit Toluidinfärbung. Brustmark: Die Ganglienzellen der Clarkeschen Säulen sind stark angeschwollen und zeigen centrale Chromatolyse und homogene Schwellung. Auf der einen Seite erscheint die Zahl der Ganglienzellen in der Clarke'schen Säule geringer, als auf der anderen. Dieselben 
Veränderungen kann man aber auch im Vorderhorn constatiren. Die Ependymzellen sind stark gewuchert.

Nach van Gieson: Die Gefässe vermehrt, stellenweise verdickt und mit Blut gefüllt. Die Glia in den Hintersträngen, besonders in den Goll'schen Strängen stellenweise gewuchert. Hier und da Corpora amylacea.

Nach Weigert-Pal: Die Markfasern in den Hintersträngen und in der Peripherie der Seitenstränge etwas gelichtet. Die Fasern, welche aus den Wurzeln nach den Clarke'schen Säulen ausstrahlen, sind auf einer Seite stärker vermindert als auf der anderen.

Nach Marchi: Wie im Halsmark.

Mit Toluidinblaufärbung. Lendenmark: Die Veränderungen der Ganglienzellen in den Clarke'schen Säulen sind sehr bedeutend. Abbild. III.

Abbildung III. Iendenmark (Clarke'sche Säule). Die Gangiienzellen zeigten verschieden starke Veränderung.

Object. Zeiss 8. Projectionsocular 2. Abstand $44 \mathrm{~cm}$.

Einige sind fast rundlich angeschwollen, wie Schatten blass gefärbt, haben im centralen Theil keine Granula und zeigen in der Peripherie blasse kleine zerfallene Granula. Der Kern ist ganz rerloren. Andere sind auch stark angeschwollen, ihr Kern ist an die Peripherie rerschoben und hat eine dünne schmale Form angenommen; um den Kern erscheinen nur spärliche Nisslizörper, sonst ist dieZelle ganz hell. Es giebt dann noch andere Ganglienzellen, welche spindelförmig aufgequollen sind, deren Centrum ganz hell geworden ist, während nur am Rande an einzelnen Stellen noch dunkel gefärbte Granula sich befinden. Hier ist der Kern ganz verschwunden. Man findet anch 
Ganglienzellen, welche diffus blau gefärbt und stark geschrumpft sind, klein zerfallene Granula zerstreut enthalten. Man hat den Eindruck eines zerfallenen Zellleibes. Auf der Seite, wo die eben beschriebenen Ganglienzellen liegen, ist die Zahl derselben in der Clarke'schen Säule deutlich vermindert. Man sieht nur 1-2 im Gesichtsfeld. Auf der anderen Seite finden sich dagegen immer 6-7. Die Ganglienzellen der Vorderhörner zeigen Vacuolen, stellenweise Atrophie.

Nach van Gieson: Die Gefässe stellenweise verdickt. Die Glia ist in den Goll'schen Strängen, im medialen Theil der Vorderstränge und in der Mitte der Seitenstränge vermehrt; besonders um die Gefässe ziemlich stark gewuchert.

Nach Weigert-Pal: Die Markfasern sind um das Sept. post. etwas vermindert. Die Fasern, welche ron den hinteren Wurzeln in die Clarke'schen Säulen einstrablen, haben auf der einen Seite etwas abgenommen.

Nach Marchi: Wie im Brustmark.

\section{Fall 3.}

C. L., 38 Jahre, Milchbändlersfrau, wurde am 1. November 1906 aufgenommen. Heredität negirt. Vater lebt gesund. Mutter gestorben an Altersschwäche. Zwei Geschwister gesund, 3-4 Geschwister klein gestorben. Als Kind immer etwas sebwach, viel Kopfschmerzen. Keine Krankheiten sonst. In der Schule sehr gut gelernt. Mit 16 Jahren erste Menses, immer regelmässig ohne Beschwerden. Nach der Schulzeit als Dienstmädchen in Stellung, dann Schneiderei gelernt. 1891 Heirath. 8 normale sehr leichte Geburten. 6 Kinder, 2 klein gestorben. In der letzten Zeit viel Kopfschmerzen. Vor 2 Tagen plötzlich Blutung ans den Genitalien, keine Stücke abgegangen.

In letzter Nacht bis 2 Uhr sehr vergnügt, fing an zu erzählen, sie müsse sterben, werde nicht wieder besser. Sprach viel unverständlich. Schlief nicht. Ass nicht. Blieb im Bett. Keine verkehrte Handlung. Heute Nachmittag klar. Erkannte ihre Umgebung. Keine Gesichts- und Gobörstäuschung. Patientin soll schon vor 5 Jahren an einer vorübergehenden Störung gelitten haben. Einige Tage vor Beginn der letzten Psychose sei sie etwas niedergedrückt gewesen. Menses öfters unregelmässig. Sitzt still, in sich versunken da, mit rathlosem Gesichtsausdruck, spricht nicht, giebt auf Fragen keine Antwort, befolgt einzelne Aufforderungen zögernd (wie Aufstehen, Hand geben).

In der Nacht ohne Schlafmittel ziemlich gut geschlafen. Widerstrebt bei der Untersuchung, die dadurch unvollkommen bleibt. Statos: graciler Knochenbau. Schlaffe Musculatur, sehr dürftiger Ernährungszustand. Schädel auf Druck und Beklopfen nicht empfindlich. Keine Kopfnarben. Pupillen untermittelweit, gleich, nicht ganz rund. $\mathrm{R} / \mathrm{L}+$.

Leichtes Zittern der Hände. Keine Motilitätsstörung. Mechanische Muskelerregbarkeit etwas erhöht. Leichtes vasomotorisches Nachröthen. Patellarreflexe ++ , Zehenreflexe plantar. Gang sicher. Thorax flach. Supra- und Intraclaviculargrube etwas eingesunken. Herzdämpfung nicht vergrössert. Töne rein. Puls 80, regelmässig, etwas klein. Abdominalorgane ohne Besonderheit. Liegt 
am Tage stuporös da, lässt passiv erhobene Extremitäten in der gegebenen Stellung. Harn angehalten, ohne Eiweiss und Zucker; spec. Gewicht 1035.

3. November. Giebt auf Aufforderung die Hände, will dann nicht wieder loslassen. Hat gestern nur 2 Schnitten Brot und einen Becher Milch zu sich genommen. Isst beute gut. Unsauber. Mutistisch.

4. November. Liegt ruhig im Bett. Stösst mitunter eigenthümlich schreiende Laute aus. Ziemiich gut gegessen. Das Essen muss ihr gereicht werden.

5. November. Heute lant, grimmassirt etwas.

15. November. Schreibt einen Brief an ihren Mann, er solle sie am Sonntag besuchen.

20. November. Abends unruhig, weint und schreit. Heute wieder klar. Weiss, dass sie im Krankenhaus ist. Gedrückter Stimmung, weint viel, sagt, sie werde nicht wieder besser.

25. November. Unruhig, ängstlich. Häufig aus dem Bett, weint, sie habe doch nichts gethan. Behauptet, sie sei bier in Kiel auf dem Bahnhof, weil hier so grosse Thüren seien.

30. November. Sehr matt, elend. Sehr still. Spricht fast garnicht. Sträubt sick sehr bei der Nahrungsanfnahme. Sehr unsauber.

1. December. Ganz verworren. Giebt auf Fragen keine Antwort, befolgt Aufforderung nicht. Liegt zu Bett, spricht unverständlich, zeitweise lallend, vor sich hin, schreit. Stösst rhythmisch gleichmässige, eigenthümliche, grunzende und schreiende Laute aus, wiederholt ein Wort oder eine Silbe andauernd lange Zeit hintereinander. Durchfall auf Opium geringer. Unsauber. Isst sehr wenig. Macht heftige wackelnde und schlenkernde Bewegungen mit Armen und Beinen, schlägt gegen die Bettbretter und im Bade gegen die Wände der Wanne.

16. December. Andauernd laut, schreit, spricht unverständlich vor sich hin. Nahrungsaufnahme gering. Durchfall.

20. December. Zunehmender Kräfteverfall. Elendes verfallenes Aussehen. Durchfall. Ruhiger.

22. December. Morgens galliges Erbrechen. Abends 6 Uhr 30 Minuten Exitus letalis.

Section: Schädelkapsel mässig dick und schwer. Dura glatt. Im Sinus long. wenig flüssiges Blut. Pia zart. Gyri and Sulci ohne Besonderheit. Hirngewicht $1199 \mathrm{~g}$. Rückenmark ohne Besonderheit. Stark abgemagerte Leiche, theilweise ziemlich flächenhafte Hautdefecte. Pleuren nicht verwachsen. Pleurahöhle leor. Im Pericard wenige Cubikcentimeter seröser Flüssigkeit. Kleines schlaffes Herz. Zarte Klappen, Herzfleisch leicht getrübt, grün bräunlich. Trachea und Schilddrüsen ohne Besonderheit. Lungen gut lufthaltig, ohne Besonderheit. In der rechten Spitze kleiner alter verlsäster Herd. Bronchialdrüsen ohne Besonderheit. Nach Eröffnung der Bauchhöhle nimmt den ganzen Raum der enorm ditalirte und gesenkte Magen ein, das Colon transvers. liegt an der Symphyse dicht auf der Blase. Nieren an normaler Stelle. Milz klein, Kapsel gerunzelt. Farbe und Consistenz ohne Besonderheit. Nebenniere ohne 
Besonderheit. Blase wenig gefüllt. Uterus klein, retroflectirt. Ovarien klein, knorplig hart. In dem enorm dilatirten Magen ist die Schleimhaut blass. Sehr starker Dünn- und Dickdarmkatarrh. Schnürfurche der Leber. Schnittfläche grün gelb, anämisch. Pankreas ohne Besonderheit.

\section{Grosshirnrinde.}

Mit Toluidinblaufärbung. 3. Stirnwindung: Die Ganglienzellen enthalten im Allgemeinen viel Pigment. Stellenweise zeigen sie homogene Schwellung, stellenweise giebt es Ganglienzellen, welche sich wie Schatten verfärbt haben, deren Kernkörperchen intensiv blau gefärbt sind. Die Capillaren sind mit Blut stark gefüllt. Trabantzellen sind ziemlich viel um die Ganglienzellen angehäuft.

Nach Weigert-Pal. Die Tangentialfasern sind theilweise stark vermindert, theilweise geschlängelt oder perlschnurartig aufgequollen. In der 2. - 3. Schicht haben die Fasern auch abgenommen. Die radiären Fasern sind stark gelichtet, haben nicht, wie normal, die Oberflächenschicht erreicht.

Nach Bielschowslry: Die extracellulären Fibrillen haben in der 1. bis 2. Schicht bedeutend abgenommen. Die kleinen und grossen Pyramidenzellen haben sich intensiv schwarz gefärttt; die Fibrillen des Zellleibes sind stark zertrümmert oder verschwunden, daher zeigt der Zellleib ab und zu helle Stellen. Die Fibrillen des Spitzenfortsatzes sind an der Ansatzstelle punktförmig zerbrochen, in weiterer Entfernung noch relativ gut erkennbar, manch. mal miteinander verklebt.

Es giebt Ganglienzellen, welche um den Kern herum unregelmässig hell geworden sind und nur in der Peripherie verlöthete Fibrillen zeigen.

Nach van Gioson. Die Capillaren, besonders zwischen den Markstrablen, zeigen in den perivasculären Räumen starke Anbäufung der Gliakerne. Die Gefässe sind mejst gefüllt und enthalten hier und da hyaline Thromben.

Mit Toluidinbla ufärbung. Vordere Centralwindung: Die Ganglienzellen bieten hier und da homogene Sehwellung. Die kleinen und mittelgrossen Pyramidenzellen sind zum Theil sehr dunkel gefärbt und haben sich sammt Kern ganz verloren. Die Fortsätze haben sich auch stark blau gefärbt, besonders die Spitzenfortsätze sind auf weitere Strecken verfolgbar und deutlich geschlängelt. Die Bcetz'schen Riesenzellen haben fast alle centrale Chromatolyse oder homogene Schwellung. Die Capillaren sind vermebrt nnd gefüllt. Trabantzellen sind im pericellulären Raum oder im Grundgewebe stark vermehrt. Manchmal scheinen sie in die Zellen eingedrungen. Die Ganglienzelien haben sich dementsprechend umgestaltet, so dass der Zellleib nach aussen concav erscheint (Abbildung I). In dem perirasculären Raum haben die Rnndzellen sich stark angehäuft.

Nach Weigert-Pal. Im Rindensaum sind stellenweise die Gliafasern stark gewuchert, verlaufen zum Theil bis in die tioferen Scbichten hinab und täuschen so manchmal Marlifasern vor. Die Tangentialfasern sind stellenweise stark rermindert, stellen weise in kleine Stücke zerfallen oder stark aufgequollen. 
In der 2.-4. Schicbt haben die Fasern bedeutend abgenommen, die radiären Fasern auch.

Nach Bielschowsky. Die Veränderungen sind wie in der 3. Stirnwindung. In den Beetz'schen Zellen liegen zerfallene und verbackte Fibrillen und circumscripte helle Stellen. Die Ganglienzellen sind stellenweise an Zahl vormindert, daher sieht es ans, als ob sie gruppenweise angeordnet wären.

Nach van Gieson. Die Veränderungen wie in der 3. Stirnwindung, aber noch stärker. Die Rundzellen zeigten in den beiden Seiten um die Gefässe streckenweise starke Anhäufung (Abbildung II).

Nacb Toluidinbla ufärbung. Hintere Centralwindung: Die Ganglienzellen zeigen mehr oder weniger homogene Schwellung. Veränderungen sind wie in der vorderen Centralwindung, nur schwächer.

Nach Weigert-Pal. Die Tangentialfasem sind stellenweise sehr gut exhalten, stellenweise mittelstark vermindert, geschlängelt und aufgequollen. Die supra- und interradiären Fasern sind etwas gelichtet; die radiären Fasern auch etwas gelichtet, mit gequollenen Fasern untermischt.

Nach Bielschowsky. Die extracellulären Fibrillen sind in der 1.-4. Schicht mehr oder weniger vermindert, besonders in der 1.-2. Schicht. Die Veränderung der Ganglienzellen wie in der vorderen Centralwindung. Ausserdem giebt es Ganglienzellen, wolche die Fortsätze verloren haben und sich unregelmässig umgestaltet haben.

Nach van Gieson. Wie in der 3 . Stirnwindung.

Mit Toluidinblaufärbung. Fissura calcarina. Die Solitärzellen haben sich hie und da ganz diffus verfärbt, der Kern ist an die Peripherie gerückt, das Kernkörperchen hat sich intensiv blau gefärbt. Die Veränderungen sind nicht bedeutend.

Nach Weigcrt-Pal. Die Tangentialfasern sind stellenweise mehr oder minder vermindert. Die supra- und interradiären Fasern stellenweise deatlich gelichtet, die radiären Fasern auch etwas.

Nach Bielschowsky. In der 1. Schioht sind die Fibrillen in kleine Stücke zerfallen und mittelstark vermindert. Die Ganglienzellen sind meist gut erhalten. Die Solitärzellen zeigen manchmal kleine Löcher durch Zerfall der Fibrillen im Zellleib.

Nach ran Gieson. Wie in dor hinteren Centralwindung.

\section{Rüekenmark.}

Mit Toluidinblaufärbung. Die Ganglienzellen im Vorderhorn zeigen starke Veränderungen. Einige Ganglienzellen zeigen Vacuolenbildung im Zelleib, andere centrale Chromatolyse.

Nach van Gieson. Die Gefässe haben sich mit Blut stark gefüllt. Man findet im hinteren Theil der Seitenstränge und in dem medialen $A$ bschnitt der Vorderstränge Glia-Wucherung.

Nach Weigert-Pal. Die Markfasern sind in der Peripherie der Gollschen Stränge etwas gelichtet. 
Nach Marchi. Schwarze Punkte sind diffus zerstreut überall vorhanden, besonders in den Burdach'schen Strängen.

Mit Toluidinblaufärbung. Brustmarli: Die Ganglienzellen in den Clarke'schen Säulen zeigen starke Chromatolyse. In der lateralen Gruppe des Vorderhorns zeigen die Ganglienzellen atrophische Veränderungen. Man kann in der Gefässwand hyaline Degeneration constatiren. Uebrige Veränderungen wie im Halsmark.

Nach van Gieson. Die Gefässe sind stellenweise verdickt. In der grauen Substanz giebt es viel Corpora amylacea. Die Gliawucherung nicht bedeutend.

Nach Weigert-Pal. Die Fasern, welche aus den hinteren Wurzeln in die Clarke'schen Säulen einstrablen, haben auf der einen Seite etwas mehr abgenommen als auf der anderen.

$\mathrm{Nach}$ Marchi. Wie im Halsmark.

Nach Toluidinblaufärbung. Die Ganglienzellen in den Ciarkeschen Säulen zeigen starke centrale Chromatolyse und sind auf einer Seite bedentend vermindert.

Die Ganglienzellen im Vorderhorn zeigen auch periphere und centrale Chromatolyse. Ependymzellen stark gewuchert.

Nach van Gieson. Die Gefässe haben sich mit Blut stark gefüllt. Die Glia ist in der weissen Substanz inselförmig gewuchert.

Nach Weigert-Pal. Die Markfasern baben in der peripheren Zone der Hinter- und Seitenstränge abgenommen. Sonst wie im Brustmark.

Nach Marchi. Wie im Halsmark.

\section{Fall 1.}

W. Ue., 25 Jahre, Schmied, wurde am 7. October 1905 aufgenommen. Angeblich keine Heredität. Patient früber gesund, in der Schule gut gelernt. Nach der Schulzeit in die Lehre beim Vater; nach dessen Tode mit 17 Jahren das Geschäft übernommen. Anstrengende Thätigkeit. Geschäft sei verschuldet gewesen, Schulden zugenommen. Seit 3 Wochen zu Bett gelegen, aber schon über ein $1 / 2$ Jahr vorher verändert. Sei sehr still geworden, babe sich zu Niemandem geäussert, glaubte, es könne ihn Niemand verstehen. Habe Unannehmlichkeiten mit der Familie gehabt. Mutter habe ein Verhältniss angefangen, wolle deshalb den Sohn aus dem Geschäft drängen. Patient fange, wenn man mit ihm rede, gleich zu weinen an, sage, er werde bald sterben müssen, weigere sich zu essen, wolle verhungern. Sage, er möchte lieber auf den Kirchhof als in die Klinik. Hat $1 / 4$ Jahr nicht mehr ordentlich gearbeitet, daher viel Kunden verloren. Die Mutter babe ihn auch schlecht gemacht. Ueber Schlaf nichts bekannt. Seit mehreren Tagen angeblich kein Stuhlgang. Kein Schwindel, Ohnmachten, Krämpfe, Kopfschmerz.

Status: Patient sitzt in starr unbeweglicher Stellung da, Kopf nach vorn gebeugt, Blick zu Boden gerichtet. Stirn in Falten. Kräftiger Knochenbau, mittlere Musculatur, mässiger Ernährungszustand. Gesicht etwas blass. Haut- 
narbe über der Nasenwurzel. Schädel auf Druck und Beklopfen nicht empfindlich.

Pupillen eng, gleich rund.

$\mathrm{R} / \mathrm{C}+\mathrm{R} / \mathrm{L}+$, A. B frei.

Augenbrauen zusammengewachsen. 7 R. Spur. $>$ L. Sprache leise, langsam, keine articulatorische Sprachstörung.

Zunge nach links, zittert, leicht belegt. Gaumenbögen gleichmässig gehoben. Rachenreflexe schwach. Uvula nach links. Grobschlägiger Tremor manuum. Quinquaud. Reflexe der OE, OE lebhaft. Mechanische Muskelerregbarkeit gesteigert. Vasomotorisches Nachröthen angedeutet. Knierellexe gesteigert. Patellarclonus angedeutet. Achillessehnenreflexe gesteigert. Fussclonus angedeutet. Zehenreflexe schwach plantar. Gang langsam, sicher. Romberg angedeutet. Grosse Nervenstämme der U. E. U. E. angeblich druckempindlich. Cremasterreflexe schwach. Abdominalreflexe lebhaft.

Pinselberührungen empfunden. Spitze und Kopf nicht zu unterscheiden. Schmerzempfindung normal. Puls 96, regelmässig, ziemlich klein, Töne rein. Lungen ohne Besonderheit. Leib etwas gespannt, links oberhalb des Nabels angeblich druckempfindlich. Urin ohne Eiweiss und Zucker. Wo hier? Krankenbaus Kiel. Datum Sonnabend (richtig) 5. October 1905. Wer hergebracht? Mein Freund. Sind Sie krank? Ja, Magenschmerzen.

8. October. Patient liegt theilnahmlos in starrer Haltung zu Bett, beschäftigt sich nicht, lrönne nicht essen, der ganze Magen sei noch voll. Es könne nicht mehr heraus, habe gar keinen Stuhlgang mehr.

10. October. Muss sehr zum Essen angehalten werden. Der Magen sei ganz voll. Habe keinen Stuhlgang mehr, es sei alles voll. Hat Stuhlgang gehabt.

18. October. Meist in halbstarrer Haltung. Die Haltung hat etwas Gezwungenes. Gesichtsausdruck starr. Kümmert sich nicht um seine Umgebung, isst jetzt besser, behauptet aber immer, er habe überhaupt keinen Stuhlgang.

19. October. Patient liegt meist in gekrümmter, gezwungener Haltung zu Bett, einen Arm unter dem auf die Brust gebeugten Kopf. Spricht nur auf Befragen, auch dann nur das Allernöthigste. Nimmt sein Essen nur, wenn es ibm vom Arzt und Pfleger eingegeben wird. Stuhlgang träge. das Essen.

28. Oetober. Im Wesentlichen ganz unverändert. Sträubt sioh gegen

Nach Hause abgeholt. Zu Hause Anfangs freier. Seit October 1906 wieder zunehmend gehemmter, zuletzt stuporös. Er wurde am 2. Juni wieder aufgenommen. Sitzt zusammengekrümmt da, Stirn in zablreiche Querfalten, Mund halb offen, Mundwinkel herabgezogen, stöhnt leicht. Anrede ruft keine Reaction hervor. Nadelstiche ebenfalls nicht. Arme fallen schlaff herab. Zeitweise Grimassiren, namentlich in den Stirnpartien. Alle Bewegungen ausserordentlich langsam und in Absätzen. Geht mit Unterstützung mit ganz kleinen schlürfenden Schritten, bringt die Füsse gar nicht vom Boden ab.

5. Juni. Sehr negativistisch, liegt dauernd zusammengekrümmt, in die 
Decken vergraben im Bett, stöhnt vor sich hin, auch Nachts oft. Isst nur auf vieles Drängen, bricht dann oft wieder aus. Spricht fast garnicht.

12. Juni. Spricht garnichts. Liegt zusammengekrümmt da, setzt Versuchen, ihn in eine andere Lage zu bringen, heftigen Widerstand entgegen. Erbricht sehr häufig, muss mühsam mit dem Löffel gefüttert werden.

2. Juli. Nimmt seine Fütterung auf Zureden, liegt unter der Decke, jammert und stöhnt viel.

7. November. Pupillen $\mathrm{R} / \mathrm{L}++$. Urin ohne Eiweiss und Zucker. Puls 72. Temperatur $36,2^{\circ} \mathrm{C}$.

2. Januar 1907. Liegt stets unter der Decke in zusammengekrümmtor Haltung. Spricht garnicht, nur nacb seinem Wein verlangt er $\Delta$ bends regelmässig. Bricht fast nach jeder Mahlzeit. Nimmt sich dazu den Spucknapf selbst vom Nachttisch, bebält ihn aber nach dem Erbrechen so lange unter der Decke in der Hand, bis er ihm fortgenommen wird. Am besten behält er noch Cacao bei sich. Stuhlgang nur auf Einlanf.

13. Februar. Stöhnt in letzter Zeit viel leise vor sich hin, schreit fast garnicht, nur nach Wein verlangt er Abends regelmässig, beklagt sich, wenn er glaubt, er habe nicht genug belommen. Verlangt manchmal auch Abends etwas zu essen, z. B. ein Käsebrot, brioht dasselbe dann auch nicht aus, nachdem ihm gesagt, er könne sonst keins mehr bekommen.

20. Februar. Isst sehr sohlecht, bricht fast alles. Soll gefüttert werden, trinkt darauf von selbst. Es wird jetzt darauf geachtet, dass er nach dem Essen die Hände nicht in den Hals steckt, seitdem kein Erbrechen.

5. April. Patient hat bisher nicht mehr gebrochen, isst gut, liegt sonst in gekrümmter Haltung, die Decke über den Kopf gezogen im Bett, spricht nicht, murmelt nur manchmal unverständlich vor sich hin, giebt nicht die Hand.

15. April. Hacht zuweilen Schwierigkeiten bein Essen, sonst ganz unverändert. Stöhnt zuweilen leise vor sich hin. Nässt oft ein.

18. April. Plötzlich Exitus letalis.

Sektion: Stark abgemagerte Leiche. Schädel mitteldick, wenig Diploe, Dura glatt spiegelnd. Im Längssinus etwas geronnencs Blut. Bei Eröfinung der Dura fliesst wenig Liquor ab; Pia in den hinteren Partien des Kleinhirns leicht getrübt. Gyri und Sulci ohne Besonderheiten. Hirngewicht 1280.

Lungen frei. Herz sehr klein, besonders rechts. Wand sehr dünn. Klappenapparate intact. Jinkes Herz blass, kleine Schwielen. Aorta eng. Milz etwas derb. Kapsel gerunzelt. Nieren ohne Besonderheiten. Nebennieren auch. Verkäste Mesenterialdrüsen. Geschwür in den unteren Partien des Dickdarms. Magen sehr klein. Schleimhaut schiefrig gefärbt.

Grosshirnrinde.

Mit Toluidinblaufärbung. 3. Stirnwindung: Die Pyramidenzellen haben sich intensiv dunkel gefärbt und lang gezogen. Die Fortsätze sind auf weitere Strecken verfolgbar. Es giebt auch Ganglienzellen, welche sehr blass verfärbt sind, deren Kern nicht erkennbar ist, oder deren Zellleib manchmal zum Theil zerfallen. Man findet Vacuolenbildung im Zellleib. Trabantzellen sind in den 
pericellulären Räumen angehäuft. Endothelkern theilweise gewuchert, um die Gefässe Rundzellen angesammelt.

Nach Weigert-Pal. Die Tangentialfasern sind stark vermindert und der Rest der zerfallenen Fasern zeigt perlschnurartige oder spindelförmige Quellung. Die supra- und interradiären Fasern sind auch bedeutend gelichtet und laufen hier und da schräg und unregelmässig. Die radiären sind auch gelichtet.

Naoh Bielschowsky. Die extracellulären Fibrillen sind in der 1. bis 4. Sehicht im Ganzen in kleine Stücke zerfallen, bedeutend vermindert, besonders in der 1.--3. Schicht. Die radiären haben auch stark abgenommen. Die Anordnung der Ganglienzellen ist verwaschen und ihre Zahl stark vermindert. Die Ganglienzellen baben fast alle Fortsätze verloren und haben sich stark umgestaltet. Der Kern ist stark schwarz gefärbt, die Fibrillen des Zellkörpers sind stark zerfallen und haben sich in schwarze Klumpen umgewandelt. Stellenweise zeigen die Ganglienzellen Schrumpfung.

Nach van Gieson. Um die Gefässe sind Gliakerne mässig stark angehäuft.

Mit Toluidinblaufärbung. Vordere Centralwindung: Die Ganglienzellen, besonders die Pyramidenzellen, sind meist geschrumptt und verjüngt oder länglich umgestaltet und sammt dem Kern dunkel gefärbt. Manchmal ist der Kern nicht erkennbar. Die Fortsätze baben sich geschlängelt und sind anf weitere Strecken verfolgbar. Es giebt Ganglienzellen, welche blass verfärbt sind und im Zellleib viel kleine Vacuolen besitzen, deren Kern sehr blass, chromatinarm, deren Körperchen sehr intensiv schwarz gefärbt ist. Die Beetz'schen Riesenzellen sind diffus dunkelblau gefärbt, alle Fortsätze deutlich verfolgbar oder die Zellen blass verfärbt und der Kern unsichtbar. Die Trabantzellen sind um die Ganglienzellen stark angehäuft. Die Gliakerne sind um die Gefässe massenhaft rorhanden. Endothelkerne stellenweise gewochert. In Grundgewebe sind die Gliakerne vermehrt.

Nach Weigert-Pal. Die Veränderungen wie in der 3. Stirnwindung, aber etwas weniger.

Nach Bielschowsky. Die extracellulären Fibrillen sind in kloine Stücke zerfallen, haben bedentend abgenommen, besonders die gröberen Fasern sind fast garnicht sichtbar. Die kleinen Pyramidenzellen sind sohwarz gefärbt und deutlich verschmälert. Die Beetz'schen Riesenzellen haben sich homogen blass yerfärbt, keine Fibrillen sichtbar; aber es giebt auch gut erhaltene Riesenzellen. Sonst wie in der 3. Stirnwindung. Die Ganglienzellen sind an Zahl vermindert.

Nach van Gieson. Wie in der 3. Stirnwindung.

Mit Toluidinblaufärbung. Die Ganglienzellen, besonders die Pyramidenzellen, sind fast alle dunkelblau gefärbt und zeigen Schrumpfung und Atrophie. Die Fortsätze, besonders die Spitzenfortsätze, sind geschlängelt und anf weitere Strecken verfolgbar. Die Zahl der Ganglienzellen hat deutlich abgenommen. Hier und da findet sich homogene Schwellung. Die Gliakerne im Grundgewebe sind stark vermehrt. Viel Trabantzellen in den pericellulären Räumen. 
Nach Weigert-Pal und Bielschowsky. Wie in der 3. Stirnwindung.

Nach van Gieson. Wie in der3. Stirnwindung, stellenweise Adrentitiaund Endothelkerne gewuchert.

Mit Toluidinblaufärbung. Fissura calcarina: Die Pyramidenzellen zeigen stellenweise atrophische Veränderungen. Die Rundzellen in der Umgebung der Gefässe angehäuft. Adventitia- und Endothelkerne gewuchert.

$\mathrm{Nach}$ Weigert.Pal. Die Veränderungen wie in der 3. Stirnwindung, aber man findet noch Tangentialfasern, welche noch hier und da auf lange Strecken verfolgbar sind.

Nach Bielschowsky. Die Veränderungen wie in der hinteren Centralwindung.

Nach van Gieson. Die Rundzellen (Gliakerne) um die Gefässe stark angehäuft. Adventitia- und Endothelkerne theilweise gewuchert.

Rückenmark.

Mit Toluidinblaufärbung. Halsmark: Die Veränderungen der Ganglienzellen nicht bedeutend; pur einige Zellen zeigen centrale Chromatolyso.

Nach van Gieson. Die Glia ist theilweise in der weissen Substanz gewuchert.

Nach Weigert-Pal. Die Markfasern sind nur wenig an der Peripherie der Seitenstränge gelicbtet.

Nach Marchi. Schwarze Punkte sind nur diffus zerstreut vorhanden.

Mit Toluidinblaufärbung. Brustmark: Die Ganglienzellen in der Clarke'schen Säule zeigen nur wenig atrophische Veränderungen. Sonst leine Veränderungen.

Nach van Gieson. Die Gefässe gefüllt. Die Glia im Ganzen viel mchr gewuchert als im Halsmark.

Nach Weigert-Pal und Marchi. Wie im Halsmark.

Mit Toluidinblaufärbung. Lendenmark: Die Ganglienzellen zeigen in den Clarke'schen Säulen centrale Chromatolyse oder sind angeschwollen, wie Schatten verfärbt und haben gar keinen Kern.

Nach van Gieson. Capillaren sind etwas rermehrt. Sonst wie im Brustmark.

Nach Weigert-Pal und Warchi. Nichts Besonderes.

\section{Fall 5.}

F. E., 28 Jahre, Telephonistin, wurde am 15. März 1906 aufgenommen. Mutter gesund, Vater an Herzbeutelwassersucht gestorben, Bruder nervös. Bis vor 4 Jahren ganz gesund, 1902 zuerst erkrankt mit Halluoinationen. Seitdem nicht völlig gesund, ging nicht mehrins A mt. Etwas manirirt. October Menses sistirt. Seit drei Wochen erregt. Warf die Tassen an die Wand. Stuhl nur auf Klysmen. Wegen Unruhe ins Krankenhaus. Auf dem Transport dahin furchtbares Schreien. Dort orientirt über Zeit und Ort, giobt fixirt auch rerständige Antwort, gewisses Krankheitsgefühl, sich selbst überlassen, sass sie 
aufrecht im Bett mit glänzenden Augen, hochrothem Gesicht, telephonirte Stunden lang täglich: "Wer dort? Sprechen Sie noch? Wo?" Völliger Negativismus, negirte jede Bemerkung, die eine andere macht. Wehrt sich gegen jede Lageveränderung. Sobald man zu ihr ins Zimmer trat, rief sie: "Gehen Sie hinaus, nein nicht guten Morgen." Dabei noch Tag und Nacht durchdringendes Schreien, dann Nahrungsverweigerung, Schlundsonde. Am rechten Knie entwickelt sich eine geröthete pralle Stelle bei Temperatursteigerung.

Am 15. März 1906 Aufnahme in die Klinik.

Status: Kräftiger Knochenbau, gut entwickelte Musculatur. Untersuchung sehr erschwert. Pupillen maximal weit, gleich rund. R/LO, R/CO (Injection), $\mathrm{AB}$ frei, VII symmetrisch. Zunge gerade, zittert, etwas trocken, gutes Gebiss. Gaumenbogen gleichmässig gehoben. Patellarreflexe lebhaft, Achillessehnenreflexe ++ , Zeben plantar. Nähere Untersuchung nicht möglich wegen motorischer Unruhe. Puls regelmässig, sehr frequent. Linker Unterschenkel stark angeschwollen bis hinauf zum Knie, an der Aussenseite, namentlich in der oberen Hälfte brettstarr, fühlt sich heisser als die Umgebung an, sehr druckempfindlich (Erysipel). 3-4 kleine oberfläohliche Decubitusstellen in der Glutaealgegend. Temperatur $40,3{ }^{\circ}$.

16. März. 40,50, sehr frequenter, kleiner Puls. Im Ganzen etwas ruhiger, weniger ängstlich, schreit noch oft laut auf. Spricht schr viel unzusammenhängend.

18. März. Andanernd hohes Fieber. Erysipel schreitet nach oben den Rücken hinauf fort. Pat. schreit laut auf, spricht unzusammenhängend. Sehr erregt, wird leicht aggressiv.

20. März. Fieber um $40^{\circ} \mathrm{C}$. herum. Sehr frequenter Puls. Noch immer sehr laut. Erkennt den Arzt als solchen.

22. März. Einnässen. Unsauber. Verweigert meistens Arzneien. Injection, da durch lautes Schreien sehr störend.

24. März. Allmählich Temperaturabfall. Heute fieberfrei. Erysipel blasst überall ab. Schreit oft anhaltend laut. Macht viel Schwierigkeiten bei der Nahrungsaufnahme, nimmt nur wenig flüssige Nahrung. Puls sehr frequent, regelmässig,"etwas klein.

1. April. Grosser Abscess an der Aussenseite des l. Unterschenkels. Es entleeren sich grosse Mengen chocoladefarbigen Eiters und nekrotische Gewebsfetzen.

2. April. Temp. am $38^{\circ}$ C. herum. In der letzten Nacht trotz Schlafmittel unruhig, wirft alles Moos aus dem Bett. Sehr tiefer Deoubitus mit schmierig eitriger Secretion.

3. Juli. Fieberfrei. Schreit viel. Verlangt Mittags schon Schlafmittel. L. Fuss stark geschwollen. Isst wenig. Elondes verfallenes Aussehen.

9. Juli. Temp. $38,8^{\circ} \mathrm{C}$. Euphorisch. Will in den Garten gehen. Schreit Abends laut yor Schmerzen.

10. Juli. Somnolenz. Unsauber. Abscess fötid riechend. Abends frequente Athmung und kleiner Puls.

11. Juni. Exitus. 
Section: Magere fettarme Leiche, Fett sehr dunkelgelb, trocken. An Lungen nichts Besonderes, überall lufthaltig. Im linken Unterlappen etwas Hypostase. Herz contrahirt fast blutleer und wenig Blutgerinnsel. Herzfleisch sehr blass. Klappen zart. Trachea enthält schaumige Flüssigkeit. Im Herzbeutel $60 \mathrm{ccm}$ seröse trübe Flüssigkeit. Bronchialdrüsen pigmentirt. Milz derb, Kapsel fettarm. Niere enthält eine haselnussgrosse Cyste, glattwandig, mit bräunlich schleimigem Inhalt. Trübung der Rinde und des Markes, Capsel gat abziehbar. Gelbliche Narbe auf der Oberfläche. Rechte Niere desgleichen, oben Cystennarbe. Linke Niere auffallend derb. Leber blass, derb, gross. Acini sehr fettreich. Pancreas ohne Besonderheiten. Magen zeigt über dem Pylorus ein rundliches erbsengrosses Geschwür. Blase stark contrahirt, enthält milchig getrübten Urin. Genitalorgane ohne Besonderheiten. Schädeldach mässig dick und schwer. Dura glatt, nicht gespannt. Längssinus enthält wenig flüssiges Blut. Pia sehr getrübt, namentlich über der rechten Hemisphäre. Gehirn in toto sehr weich. Nerven und Gefässe ohne Besonderheiten. Windungen oben etwas abgeplattet. Rückenmark gleichfalls sehr weich. Hirngewicht 1227.

\section{Grosshirnrinde.}

Mit Toluidinblaufärbung. Die Pyramidenzellen sind im Allgemeinen dunkel oder blass gefärbt und lang gezogen; manchmal findet man Zellen, welche blass verfärbt sind, deren Kern blass und blasig, chromatinarm und von hellem Hof umgeben sind. In der Umgebung der Gefässe sind Randzellen angehäuft.

Nach Weigert-Pal. Die Tangentialfasern sind in kleine Stücke zerfallen, stellenweise aufgequollen, geschlängelt und mässig vermindert. Die supra- und intraradiären Fasern sind deutlich vermindert; die radiären auch.

$\mathrm{Nach} \mathrm{Bielschowsky.} \mathrm{Die} \mathrm{extracellulären} \mathrm{Fibrillen} \mathrm{sind} \mathrm{in} \mathrm{der} \mathrm{1.} \mathrm{bis}$ 2. Schicht mittelstark vermindert. Die Pyramidenzellen besitzen gut erhaltene äussere Form, doch sind Zellleib und Kern schwarz gefärbt, manohmal ist der Spitzenfortsatz wie fortgehackt. Stellenweise sind die Ganglienzellen wie Schatten rerfärbt und nur die Kerne haben sich intensir schwarz abgezeichnet.

Nach van Gieson. Rundzellen (Gliakerne) um die Gefässe angehäuft.

Mit Toluidinblaufärbung. Vordere Centralwindung. Die Veränderungen fast wie in der 3. Stirnwindung. Die Pyramidenzellen zeigen fast alle atrophische Veränderungen. Die Anzahl der Zellen ist stellenweise deutlich vermindert. Die Beetz'schen Riesenzellen haben sich homogen blass verfärbt und manchmal den Kern verloren. Die Capillaren sind vermehrt und gefüllt. Wan findet an der Gefässwand Pigment. Trabantzellen sind in dem pericellulären Raum ang'ehäuft.

Nach Weigert-Pal. Die l'angentialfasern sind gut erhalten wie normal, aber sie sind viel mehr geschlängelt und aufgequollen als normal.

Nach Bielschowsky. Die Fibrillen sind in der 1. Schicht in feine Massen zerfallen, mittelstark vermindert. Die kleinen und mittelgrossen Pyramidenzellen weisen Verjüngung und Atrophie auf. Es giebt grosse Pyramidenzellen, welche durch Verschwinden der zerfallenen Fibrillen kieine Löoher 
zeigen. Die Beetz'schen Riesenzellen zeigen theils im Zellleib kleine Löcher, theils sind sie diffus blass verfärbt und der Kern ist an die Peripherie gerückt.

Nach van Gieson. Um die Gefässe leichte Anhäufung der Gliakerne.

Mit Toluidinblaufärbung. Die Ganglienzellen halsen sich im Allgemeinen blass verfärbt. Einige Pyramidenzellen sind atrophisch, aber nicht bedeutend. Stellenweise zeigen die Zollen homogene Schwellung. Gefässveränderung wie in der vorderen Centralwindung.

Nach Weigert-Pal. Die Veränderung wie in der vorderen Centralwindung, aber etwas schwächer.

Nach Bielschowsky. In der 1. Schicht sind die Fibrillen in kleine Stücke zerfallen, stellenweise stark vermindert. Zellveränderung wie in der vorderen Centralwindung.

Nach van Gieson. Wie in der vorderen Centralwindung.

Nach Toluidinblaufärbung. Die Ganglienzellen zeigen stellenweise Atrophie, stellenweise bieten die Solitärzellen homogene Schwellung. Die Voränderungen sind nicht stark, Mastzellen in der Gefässwand.

Nach Weigert-Pal. Die Tangentialfasern sind stellenweise etwas vermindert; die supra- und intraradiären Fasern auch.

Nach Bielschowsky. Die extracellulären Fibrillen sind in der 1. bis 2. Schicht ziemlich stark vermindert. Die Ganglienzellen haben gut erhaltene äussere Form, sind jedoch schwarz gefärbt.

Nach van Gieson. Wie in der hinteren Centralwindung. Die Gefässe ver dickit.

\section{Rückenmark.}

Mit Toluidinblaufärbung. Die Ganglienzellen sind an Zabl im Vorderhorn etwas vermindert. Sonst zeigen sie pigmentöse Degeneration und centrale Chromatolyse.

Nach van Gieson. Die Gelässe sind stellenweise verdickt, die Glia hier und da gewuchert.

Nach Weigert-Pal. Die Markfasern sind in der Peripherie der Hinterstränge etwas gelichtet.

Nach Marchi nichts Besonderes.

Brustmark. Mit Toluidinblaufärbung. Die Ganglienzellen zeigen in den Clarlie'schen Säulen starke centrale Chromatolyse.

$\mathrm{Nach}$ van Gieson wie im Halsmark.

Nach Weigert-Pal und Marchi. Keine bedeutende Veränderungen.

Mit Toluidinblaufärbung. Lendenmark: Die Ganglienzellen haben an Zahl stark abgenommen. Die Veränderungen sind besonders stark in der Clarke'schen Säule, hier meist centrale Chromatolyse.

Nach ran Gieson. Die Zahl der Ganglienzellen ist bedeutend vermindert. Die Glia ist in allen Strängen hier und da inselförmig gewuchert.

Nach Weigert-Pal, Die Fasern sind in der Umgebung rom Sept. post. etwas gelichtet.

Nach Marchi wie im Halsmark. 


\section{Fall 6.}

D. R., Wittwe, 53 Jahre alt, wurde am 27. October 1906 aufgenommen. Angeblich keine hereditäre Belastung. Seit 26 Jahren offenes Bein. In den letzten Jahren schwach. Seit letzter Zeit mitunter ohne Grund geweint. Seit längerer Zeit geschwollen im Gesicht und an den Beinen, seit längerer Zeit vergesslich. Am Sonntag den 21. October Abends blass, ängstlich, jammerte: „Sie müsse sterben". War bange, sagte, sie möchte gern noch leben. Wurde aufgeregter, jammerte, sie sei arm, könne nicht mehr existiren. Sah Gestalten, hörte Stimmen, nicht gewaltthätig. Bildete sich ein, sie verbrauche zu viel. Appetit gut. Patientin wird immer lauter.

Am 27. October. Gegen 11 Uhr Abends gebracht. Muss auf die Abtheilung getragen werden. Laut, jammerte und klagte. Gehen nicht möglich. Setzt kein Bein an. Auf $10 \mathrm{~g}$ Paraldeliyd Schlaf. Bei der Morgenvisite schwer zu erwecken. Antwortete auf Fragen nicht. Sieht sich erstaunt um.

Status: Pockennarbe im Gesicht. Kräftiger Knochenbau, ziemlich guternährt. Strabismus divergens. Pupillen different, l. $>$ r. rund. R./L. +R./C. und A.B. nicht zu prüfen. VII anscheinend symmetrisch. Zunge gerade, zittert, stark belegt. Keine Lähmung. Mechanische Muskelerregbarkeit nicht erhöht. Leichtes vasomotorisches Nachröthen. Patellarreflexe deutlich. Kein Fussclonus. Zehen plantar. Rechter Unterschenliel ödematös. Starke Varicen; an der Innenseite handtellergrosse granulirende Wundfläche (altes Ulous).

Innere Organe, soweit Untersuchung möglich, obne Besonderheit. Herztöne leise. Puls 80 , regelmässig. Arterien eiwas rigide. Urin ohne Eiweiss und Zucker. Hat den ganzen Tag geschlafen, nicht gesprochen, nicht gegessen. Schlockte nicht. Einmal auf Anrufen genicht.

29. October. Liegt heute ruhig zu Bett, spricht nicht, nässt ein. Kramt Abends und Nachts viel im Bett herum, wühlt, versucht heraus zu klettern. Auf $5 \mathrm{~g}$ Paraldehyd Schlaf.

30. October. Sitzt ruhig im Bett. Packt mit dem Bettzeug. Kann mit beiderseitiger Unterstützung etwas gehen.

2. November. Unverändert. Sitzt im Bett, rutscht an das Fussende des Bettes, bält sich mit beiden Händen fest und rüttelt am Bett, starrt dabei in's Leere. Packt viel mit dem Bettzeug. Oefters ziemlich unruhig, will aus dem Bett heraus. Murmelt unverständlich vor sich hin. Antwortet auf Fragen nicht. Nahrungsaufnahme mässig.

7. November. Liegt mit geschlossenen Augen theilnahmlos im Bett. Bei passiven Bewegungen widerstrebend.

11. November. Liegt theilnahmlos im Bett. Spricht nicht. Giebt auf Fragen keine Antwort. Nabrungsaufnahme geringer. Unsauber.

15. November. Eitriger Ausfluss aus dem linken Ohr. Kein Fieber. Mittelohreiterung.

18. November. Sitzt oder liegt ruhig im Bett. Blickt sich rathlos um. Ist widerstrebend. Mutacismus. Nässt ein. Nahrungsaufnahme ziemlich gut. Packt mit dem Bettzeng. 
1. December. Heute dem Arzt gegenüber sehr abweisend.

8. December. Macht lebhafte Wackel- und drohende Bewegungen mit den Armen und Händen und heftiges Nicken und Schütteln des Kopfes dabei. Wehrt mit den Händen ab, als der Arzt kommt. Macht Schwierigkeiten bei der Nahrungsaufnahme.

13. December. Packt mit dem Bettzeng. Spricht andauernd leiseunzusammenhängend vor sich hin. Abends laut. Auf $6 \mathrm{~g}$ Paraldehyd guter Schlaf. Zerfahrener Gedankengang.

20. December. Unverändert. Entblösst sich oft, sträubt sich sehr bei der Nahrungsaufnahme.

21. December. Wird nach der $\Lambda$ bendvisite in ein anderes Bett getragen. Dabei plötzlich Exitus.

Section: Schädeldach enorm dick und schwer, die Nähte stellenweise ca. $1-1^{1 / 2} \mathrm{om}$ breite, etwas vertiefte rauhe Furchen. Im Sinus longitudinalis flüssiges Blut. Dura glatt. Gyri im Parietallappen besonders abgeflacht. Furchen desselben etwas verstrichen. Nerven und Gefässe frei. Rückenmark ohne Besonderheit. Lungenemphysem. Trübe Schwellung des Herzens. Hydronephrose der linken Niere. Milz gross.

\section{Grosshirninde.}

Mit Toluidinblaufärbung. 3. Stirnwindung: Die Pyramidenzellen sind länglich und intensiv schwacz gefärbt, manchmal sehr blass verfärbt und der Kern verloren. Die Zahl der Ganglienzellen etwas vermindert. Um die Gefässe sind Rundzellen stellenweise stark angehäuft; in der Gefässwand findet man gelblichgrünliches oder braunes Pigment. Endothelkerne gewuchert.

Nach Weigert-Pal. Die Tangentialfasern sind im Vergleich mit normalem Präparat etwas vermindert, nicht deutlich, aber die Quellung der Fasern erscheint viel mobr als normal. Die supra- und interradiären Fasern sind theilweise stark gelichtet; die radiären auch.

Nach Bielschowsky. Die Fibrillen haben in der 1.-3. Schicht stark abgenommen, besonders in der 1. Schicht selten gröbere Fasern vorhanden. In der 2.-3. Schicht auch die Fibrillen in kleine Stücke zerfallen, selten auf weitere Strecken verfolgbar. Die radiären Fibrillen sind auch gelichtet. Die Ganglienzellen haben im Allgemeinen gut erhaltene Form, sind dunkel gefärbt, und die Fibrillen des Zellleibes haben sich in schwarze Klumpen umgewandelt.

Naoh van Gieson. Die Gefässe hier und da verdiclit; in den perivasculären Räumen Rundzellen angehäuft.

Mit Toluidinblaufärbung. Vordere Centralwindung: Die Pyramidenzellen sind rundlich angeschwollen; der Kern ist an die Peripberie gerückt. Das Centrum des Zellleibes ist fast ganz hell und die feinen Granula nur in der Peripherie zu sehen. Es giebt Zellen, welche stark angeschwollen sind, keinen Kern besitzen und fein granulirt an der Peripherie mit Pigment versehen sind. Man findet Zellen, welebe sehr blass verfärbt, schwammiges Protoplasma zeigen, deren Kern blass und blasig ist. Die Beetz'schen Riesenzellen sind meist rundlich aufgequollen und haben chromatische Veränderungen. 
Die kleinen Pyramidenzellen zeigen stellenweise atrophische Veränderungen. Capillaren vermehrt und stark gefüllt. Endothel- und Adventitiakerne stellenweise gewuchert. Die Trabantzellen sind um die Zellen stark angehäuft. Sonst wie in der Stirnwindung.

Nach Weigert-Pal. Die Tangentialfasern sind theilweise stark vermindert, theilweise in Maasse zerfallen und stark aufgequollen. Die supraund interradiären Fasern auch in Stücke zerfallen und vermindert. Die radiären auch.

Nach Bielschowsky. Die Fibrillen sind in der 1.-3. Schicht stark - vermindert. Die radiären Fibrillen sind in Bruchstücke zerfallen, erreichen nicht die obere Rindenschicht, wie normal. Die kleinen und grossen Pyramidenzellen sind stellenweise verjüngt, lang gezogen, stellenweise ihre Fortsätze abgehackt. Uebrige Ganglienzellen sind im Allgemeinen geschrumpft, aber die Fortsätze sind noch gut erhalten. Es giebt kleine Pyramidenzellen, deren Kern intensiv sohwarz gefärbt und deren Zellleib und Spitzenfortsatz körnig zerfallen sind. Die Beetz'schen Riesenzellen enthalten viel Pigment; in einigen Zellen findet man grosse Vacuolen.

Nach van Gieson. Wie in der 3. Stirnwindung.

Nach Toluidinblaufärbung und Weigert-Pal. HintereCentralwindung: wie in der vorderen Centralwindung.

Nach Bielschowstry. Die Fibrillon sind in der 1. Schicht etwas rermindert, in der 2. Schicht klein zerfallen. Die Ganglienzellen haben ibre Fortsätze verloren und sich sohwarz gefärbt, und die Fibrillen des Zellleibes sind in körnige Massen zerfallen. Die kleinen Pyramidenzellen sind stark zerstört, der Kern hat sich intensiv schwarz gefärbt. Im Zellleib der grossen Pyramidenzellen findet man mehrere kleine Löcher, welche länglich oder rundlich oder unregelmässig sind.

Nach ran Gieson. Wie in der vorderen Centralwindung.

Mit Toluidinblaufärbung. Fissura calcarina: Solitärzellen zeigen theilweise homogene Schwellang.

Nach Weigert-Pal. Fast normal.

Nach Bielschowsky. Die extracellulären Fibrillen sind in der 1. bis 2. Sehicht stark vermindert. Die Ganglienzellen haben meist gut erbaltene äussere Form; aber sie haben sich schwarz gefärbt.

Nach ran Gieson. Um die Gefässe sind Gliakerne massenhaft angehäuft.

\section{Rückenmark.}

Mit Toluidinblaufärbung. Halsmark: Die Ganglienzellen zeigen im Vorderhorn centrale Chromatolyse und homogene Schwellung. Ependym: zellen sind stark gewuchert.

Nach van Gieson. Die Glia ist in den Goll'schen Strängen und in der Mitte der Seitenstränge gewuehert. Gefässe stellenweise verdickt.

Nach Weigert-Pal. Die Markfasern sind in der Umgebung des Sept. post. und im hinteren Theile der Seitenstränge etwas gelichtet. 
Nach Marchi. Keine besonderen Veränderungen.

Mit Toluidinblaufärbung. Brustmark: Die Ganglienzellen in den Clarke'schen Säulen zeigen homogene Schwellang, im Vorderhorn theilweise centrale Chromatolyse.

Nach van Gieson. Stellenweise die Glia in der weissen Substanz gewuchert, sonst wie im Halsmark.

Nach Marchi. Keine besonderen Veränderungen.

Nach Toluidinblaufärbung. Lendenmark: Wie im Brustmark.

Nach Weigert-Pal. Die Fasern sind in der Mitte der Goll'schen Stränge, in der Peripherie der Seitenstränge und in der medialen Seite der Vorderstränge etwas gelïchtet.

\section{Fall $\%$}

I. W., Schuhmacher, 45 Jahre alt, wurde am 19. März aufgenommen. Angeblich keine Heredität. Patient sei gesund gewesen bis zum 22. Lebensjahre. Kein Potator. Nie Ohnmacht oder Krämpfe, Schwindel oder Kopfsehmerzen. Er sei eines Sonntagsabend ausgewesen, am anderen Morgen habe er irre geredet. Sei mitunter aufgeregt gewesen, habe aber noch gearbeitet. Sei dann allmählioh ruhiger goworden. Er sei etwas sonderbar geblieben, habe ganz für sich gelebt. Er hat bis jetzt gearbeitet. Als jetzt das Haus verkauft wurde, in dem er mit seinem Bruder gelebt, wollte er nicht heraus. Musste schliesslich, als es abgerissen wurde, mit Gewalt in den Sanitätswagen gebracht werden.

Status: Graciler Knochenbau, schlechte Musculatur und Ernährung, Gesicht etwas blass, Schädel auf Druck und Beklopfen anscheinend empfindlichi. Cornea rechts vollkommen weisslich getrübt, völlig undurchsichtig. Rechter Bulbus weicher als links. Linke Pupille mittelweit, nicht ganz rund. R/L † $\mathrm{R} / \mathrm{C}$ und $\mathrm{A}$. B. nicht zu prüfen. $7 \mathrm{~L}>\mathrm{R}$. Tremor man. Quinquaud nicht deutlich. Brustkorb eingesunken. Mechanische Muskelerregbarkeit nicht gesteigert. Vasomotorisches Nachröthen +, Kniereflexe gesteigert, Achillesreflexe anch. Clonus wegen des heftigen Spannens nichtzu prüfen. Zehen plantar. Nadelstiche erregen keine A bwehrbewegungen, Patient verzieht keine Miene, auch nicht beim Durchstechen einer Hautfalte. Er giebt aber an, den Stich zu empfinden. Bei Stichen in's Septum narium wehrt er ab. Kein Romberg. Puls 116, regelmässig. Arterien etwas rigide. Herztöne rein. Lungen ohne Besonderheit. Leib weich, anscheinend nicht druckempfindlich. Gang mit gebeugten Knien, schlürfend, doch sicher. Urin ohne Eiweiss und Zucker.

Patient sitzt in sich versunken auf dem Stuhl, zittert, grimassirt, reagirt meist garnicht auf Ansprechen, befolgt Aufforderungen nicht, spielt zuweilen mit Daumen und Zeigefinger, als ob er Pechdraht macht. Sagt auf Befragen: "Ich weiss nicht".

25. März. Liegt zu Bett, spricht nicht, sehr ablehnend gegen alles. Hat seit mehreren Tagen nicht gegessen. Sondenfütterung.

26. März. Heute wieder Sondenfütterung. Hat sich nicht gesträubt. Steht 
dann auf, zieht sich an. Geht nach seinem Bette, legt sich. Steht $1 \frac{1}{2}$ Stunden später auf, um auf's Closet zu gehen. Fällt dabei plötzlich um: Exitus.

Section: Schädeldach sehr dick, viel Diploe, mässig schwer. Pia glatt. Im Sinus long. ziemlich viel schwarzes dünnflüssiges Blut. Pia milchig getrïbt, verdickt, durch Flüssigkeitsansammlung stark abgehoben, lässt sich in Fetzen abziehen. Gyri ohne Besonderheit. Sulci klaffen etwas. Nerven an der Bașis frei. N. opticus rechts schmal. Arterien starrwandig. Bei Abtrennung der hinteren Wand des rechten Bulbus mit der Papille zeigt sich der Glaskörper zu einer festen bräunlichen, knochenähnlichen Substanz verändert. Rückenmark ohne Besonderheit. Hyperämie der indurirten Niere mit zablreichen flachen Narben. Sehr starkes Lungenödem. Geringer Pleuraerguss. Pleuraspitzenschwielen beiderseits. Narbe des linken Unterlappens mit darunter liegendem erbsengrossen Kalkkorn. Fettarchwocherung des rechten Ventrikels und subendocardiale Fettlappen. Fensterung der Pulmonalklappen, Varix im rechten Vorhof mit Phlebolit. Verdichtung der Mitralklappenränder und der Sehnenfäden, Fensterung der Aortaklappen. Verwachsung und geringe Herabsinkung derselben. Chronische Endoarteriitis der Aorta. Unregelmässiger: Defect des linken Kehldeckelrandes. Verkalkte Bronchialdrüsen. Gallertkropf. Kleine indurirte Leber. Schlaff atrophische Milz. Kleine Blutung im Dünndarm und Coecum. Thromben und Phlebolithen im Plexus vesicalis.

\section{Hirnrinde.}

Mit Toluidinblau färbung. 3. Stirnwindung: Dje Ganglienzellen zeigen stellenweise atrophische Veränderung, stellenweise homogene Schwellung. Die Gefässe strotzend gefüllt, die Capillaren vermehrt. Viel Trabantzellen um die Ganglienzellen. Im perivasculären Raum Gliakerne wenig vorbanden.

Nach Weigert-Pal: Die Tangentialfasern sind stellenweise etwas vermindert, stellenweise gut erhalten. Die supra- und interradiären Fasern auch etwas gelichtet.

Nach Bielschowsky: Die Fibrillen sind in der ersten Schicht im Vergleich mit normalem Präparat etwas vermindert. Die kleinen und grossen Pyramidenzellen haben meist die äussere Form gut erhalten, doch hat der Kern sich intensiv sch xarz gefärbt, und die Fibrillen des Zellleibes sind stark zerfallen. Es giebt Pyramidenzellen, welche im Zellleib Vacuolen haben oder blass verfärbt und gar keinen Kern haben.

Nach van Gieson: Um die Gẹässe mässige rundzellige Anhäufung.

Vordere Centralwindung. Nach Toluidinblaufärbung: Die kleinen Pyramidenzellen zeigern stellenweise atrophische Veränderung. Die grossen Pyramidenzen und Beetz'schen Riesenzellen stellen theilweise homomogene Schwellung dar. Gefässe vermehrt und gefüllt. Wenig rundzellige Anhäufung um die Gefässe. Viel Trabantzellen um die Ganglienzellen. Endothelund Adventitiakerne gewuchert.

Nach Weigert-Pal: Die Fasern sind im Allgemeinen gut erhalten, stellenweise etwas vermindert. Aufquellung der Fasern stärker als normal. 
Nach Bielschowsky: Die Fibrillen sind in der ersten Schicht meist klein zerfallen. Die Pyramidenzellen haben hier und da die Fortsätze verloren oder abgehackte. Sonst Zellveränderung wie in der 3. Stirnwindung.

Nach van Gieson: Die Capillaren gefüllt. Sonst wie in 3. Stirnwindung.

Hintere Centralwindung. Mit Toluidinblaufärbung: Die mittelgrossen Pyramidenzellen haben sich dunkel blau gefärbt. Die Spitzenfortsätze sind auf weitere Strecken verfolgbar und manchmal geschlängelt. Sonst. haben sie sich wie Schatten verfärbt and verjüngt. Die Ganglienzellen zeigen hier und da homogene Schwellung. Die Adventitia- und Endothellerne sind stellenweise gewuchert.

Nach Weigert-Pal: Die Markfasern sind stellenweise etwas vermindert. Die radiären Fasern sind ziemlich stark aufgequollen und gelicbtet.

Nach Bielschowsky: Die extracellnlären Fibrillen sind in der ersten Schicht stellenweise ziemlich stark vermindert, stellenweise sehr gut erhalten, in der zweiten Schicht auch klein zerfallen und stark abgenommen.

Die kleinen und grossen Pyramidenzellen haben die gut orhaltene äussere Form, doch sind sie schwarz gefärbt und die Fibrillen des Zellleibes in körnige Massen zerfallen.

Nach van Gieson: Wie in der vorderen Centralwindung.

Fissura calearina. Mit Toluidinblaufärbung: Die Ganglienzellen zeigen stellenweise Chromatolyse und der Kern istin die Peripherie gerückt. Gefässe verdickt; an der Gefässwand findet man Pigment. Theilweise Endothelkerne gewuchert.

Nach Weigert-Pal: Die Markfasern nicht vermindert; aber sie sind viel kleiner als normal, zerfallen und aufgequollen.

Nach Bielschowsky: Die Fibrillen sind in der ersten Schicht in Bruchstücke zerfallen. Die Veränderungen der Ganglienzellen wie in der hinteren Centralwindung. Die Solitärzellen zeigen manchmal kleine helle Stellen im Zellleib.

Nach van Gieson: Wie in der 3. Stirnwindung.

\section{Rückenmark.}

Ha.lsmark. Mit Toluidinblaufärbung: Die Ganglienzellen im Vorderhorn sind an Zahl etwas vermindert und zeigen Chromatolyse und Atrophie. Capillaren gefüllt, Markzellen in der Gefässwand.

$\mathrm{Nach}$ van Gieson: Nichts Besonderes.

Nach Weigert-Pal: Die Fasern sind im oberen Theil der Goll'schen Stränge etwas gelichtet.

Nach Marchi: ohne Besonderheit.

Brustmark. Mit Toluidinblaufärbung: Die Ganglienzellen in der Clarke'sehen Säule zeigen centrale Chromatolyse und homogene Schwellnng. Uebrige Veränderungen wio im Halsmark.

Nach Weigert-Pal: Die Markfasern sind in den Goll'schen Strängen 
etwas vermindert. Die Fasern, welche aus hinteren Wurzeln in die Clarke 'sche Säule ausstrahlen, an einer Seite etwas abgenommen.

Nach Marchi: Wio im Halsmark.

Lendenmark. Mit Toluidinblaufärbung: Die Veränderungen der Ganglienzellen wie im Brustmark. Markzellen in der Gefässwand.

Nach van Gieson: Glia in den Hintersträngen granulirt.

Nach Weigert-Pal und Marchi: Wie im Brustmark.

\section{Fall 8 .}

S. G., Schifferstochter, 51 Jahre alt, wurde am 21. Juni aufgenommen.

Blutsverwandtschalt negirt. Eine Schwester mit 30 Jahren geisteskrank in Friedrichsberg gestorben an Lungenentzündung. Matter Schlaganfall, gelähmt. Vater 1888 gestorben, Wassersucht. 3 Brüder und 2 Schwestern gesund. Als Kind nie krank. In den letzten Jahren ölters an Erysipel gelitten, am Fuss. In der Schule gut gelernt, fleissig. Ueber erste Menses nichts bekannt. Seit ca. 5 Jahren Menopause. Klagte viel über den Magen. Immer rubig. Seit Tagen unrubig, spricht viel und laut, klopft fortwährend auf den Tisch. Schreibt alles durcheinander. Spricht viel vom Heirathen, hat früher nie davon gesprochen. Spricht von ihrem Bräutigam, hat aber keinen. Die Nachbarn bätten sie beleidigt. Angehörige seien an der Thür, man solle sie herein lassen. Spricht von $12000 \mathrm{Mk}$, die sie habe, und von ihrem Brautkleid. Seit drei Tágen zu Bett. Bis dahin gearbeitet. Seit 2 Tagen nichts gegessen: Dürfte nichts essen, denn sonst bekomme sie Strafe. Sehr sehlechter Schlaf und Strhlgang. (Wo hier?) Krankenhaus Kiel. Zeitlich nicht orientirt. Fängt an zu erzählen, spricht von ihrem Liebsten. Spricht andauernd sehr laut. Pupillen sehr eng. $\mathrm{R} / \mathrm{L}+\mathrm{l}$. minimal. Heitere Stimmung.

2. Juli. In der Nacht gut geschlafen, wegen Nahrungsverweigerung Sondenfiitterung. Heute ruhiger.

Status: Graciler Knochenbau, schlaffe Musculatur. Dürftiger Ernährungszustand. Blasses verfallenes Aussehen. Schädel auf Druck und Beklopfen nicht empindlich. Keine Kopfnarbe. Pupillen: Miotisch verzogen. $\mathrm{R} / \mathrm{L}+$ minimal. Augenbewegung frei. VII l. $>$ r. Zunge gerade, zittert, stark belegt, starker Foetor ex ore. Gebiss defect. Sprache obne articulatorische Störung. Leichter Tremor manuum. Keine Motilitätsstörung. Gelenke frei. Mechanische Erregbarkeit leicht erhöht. Leichtes vasomotorisches Nachröthen..

Patellarreflex lebhaft. Kein Patellarclonus. Achilles lebhaft. Kein Fussclonus. Zehen plantar. Gang sicher. Kein Romberg. Sensibilität, soweit zu prüfen, obne gröbere Störung. Schmerzenıfindung normal. Mässiger Schnürthorax. Lungen ohne Besonderheit. Leichtes Emphysem. Herzdämpfung nicht vergrössert. Töne rein. Puls regelmässig, 80. Arterien etwas rigide. Abdominalorgane ohne besondere Beschaffenheit. Urin ohne Eiweiss und Zucker. Als sie zum Closett geführt wird, Ohnmachtsanwandlung. Puls klein. Isst nicht, wird gefüttert.

22. Juli. In der Nacht zeitweise sehr laut. Spricht viel vor sich hin. 
Hat nur einen Becher Milch genommen. Sondenfütterung. Abends $39,5^{0}$ ohne nachweisbaren Grund. Isst nicht. Fütterung meistens erbrochen.

23. Juli. Andauernd Fieber. Spricht unverständlich und unzusammenhängend vor sich hin. Abstinirt.

25. Juli. Fieber im Rückgang. Spuckt schleimig-eitriges Sputum aus. Spricht unverständlich vor sich hin. Isst nicht. Sondenfütterang. Unsauber.

28. Juli. Wieder hohes Fieber. R/L. †. Sonst unverändert. Linke Unterbauchgegend scheint druckempfindlich.

29. Juli. Andauernd hohes Fieber. L. Handgelenk geschwollen, sehr stark schmerzbaft auf Druck und Bewegung. Verband. Ruhigstellung.

30. Juli. Links. Fussgelenksgegend geschwollen, auch Dorsum pedis nimmt an der Schwellung theil. Am Malleolus int. Haut leicht geröthet. Druck schmerzhaft. Alkoholverband. Verfallenes Aussehen. Apathisch. Spricht unverständlich vor sich hin. Ruft öfters "Helene". Durchfall, sehr unsauber. Abstinirt. Sondenfütterung.

1. August. Beide Ell bogengelenke geschwollen, auf Druck und Bewegungen schmerzhaft. Andauernd hohes Fieber. Jammert. Spricht unverständlich vor sich hin. Abstinirt. Unsauber.

2. August. Verfallenes Aussehen. Mittags Puls laum fühlbar. Campherinjection. Herztöne rein. $6 \mathrm{Uhr} 30 \mathrm{Min}$. Abends Exitus.

Section: Schädeldach dünn, durchscheinend. Dura glatt. Im Sinus longitud. ziemlich viel blutige seröse Flüssigkeit. Beim Abziehen der Dura fliesst viel Flüssigkeit ab. Pia leicht getrübt. Gyri und Sulci, Gefässe und Nerven frei. Rückenmark auch frei. Pleuritis. Alter schwieliger Herd in der linken Lungenspitze. Hypostase beider Unterlappen. Beginnende eitrige Pleuritis. Im Herzbeutel ca. $50 \mathrm{ccm}$ eitrige Flüssigkeit. Chronische Gastritis. Septische Milz.

\section{Grosshirnrinde.}

3. Stirnwindung: Mit Toluidinblaufärbung: Die Pyramidenzellen zeigen stellenweise homogene Schwellung oder sie sind wie Schatten verfärbt und baben gar keinen Kern. Die Gefässe bis in die Capillaren gefüllt. Hier und da die perivasculären Räume erweitert, darin Rundzellen angehäuft. Stellenweise kleine Blutungen.

Nach Weigert-Pal: Die Tangentialfasern sind in der 1. Schicht stark vermindert; übrige Fasern auch stark vermindert, theilweise deutlich aufgequollen.

Nach Bielschowsky: Die extracellulären Fibrillen sind in kleine Stücke zerfallen, stellenweise stark vermindert. In der 2 . Schicht auch stark gelichtet. Die Ganglienzellen sind meist gut erhalten, der Kern ungefärbt und die Spitzenfortsätze lange verfolgbar. Die Fibrillen des Zellleibes und der Fortsätze ergeben ein klares Bild. Hier und da giebt es Ganglienzellen, in denen die Fibrillen in lörnige Masse zerfallen und mehrere kleine belle Stellen zu finden sind.

Nach van Gieson: Capillaren gefüllt; Endothelkerne granulirt. 
Mit Toluidinblaufärbung: Vordere Centralwindang: Wie in der 4. Stirnwindung.

Nach Weigert-Pal: Die Markfasern sind in der 1. Schicht im Ganzen in kleine Stücke zerfallen, theilweise aufgequollen und stark vermindert. Die Fasern, welche schräg und quer laufen, haben in der 2.--3. Schicht anch stark abgenommen. Die radiären auch stark gelichtet.

Nach Bielschowsky: Die extracellulären Fibrillen sind in der 1. bis 2. Schicht mittelstark zerfallen. Die Pyramidenzellen haben gut erhaltene, äussere Form, die Fortsätze sind verloren oder wie abgehackt. Der Kern hat - sich stark tingirt; die Fibrillen des Zellleibes sind in körnige Masse umgewandelt. Die Beetz'schen Riesenzellen, in denen dic Fibrillen in Stücke zerfallen sind, tragen im Zellleib unregelmässige Löcher.

Nach van Gieson: Stellenweise sind die Gliakerne um die Gefässe ziemlich stark angehäuft.

Hintere Centralwindung: Mit Toluidinblaufärbung: Wie in der 3. Stirnwindung.

Nach Weigert-Pal: Wie in der vorderen Centralwindung, aber etwas schwächer.

Nach Bielschowsky: Die extracellulären Fibrillen sind in der 1. bis 2. Schicht mittelstark vermindert. Veränderungen der Ganglienzellen wie in der vorderen Centralwindung.

Halsmark: Nach Weigert-Pal: Die Markfasern sind etwas um das Sept. post. gelichtet.

Nach Marehi: Kerne bemerkenswerthe Veränderung.

Brustmark: Nach Toluidinblaufärbung: In beiden Vorderhörnern findet man nur einige diffus blass verfärbte Ganglienzellen, sonst garnichts. In den Clarke'schen Säulen sind die Ganglienzellen an Zahl stark vermindert, die noch übrig gebliebenen Zellen zeigen centrale Chromatolyse oder homogene Schwellung. Ependymzellen gewuchert.

Nach ran Gieson: Wie im Halsmark.

Nach Weigert-Pal: Die Fasern, welche aus den hinteren Wurzeln in die Clarke'schen Sänlen einstrahlen, sind vermindert auf einer Seite.

Nach Marchi: Wie im Halsmark.

Lendenmark: Mit Toluidinblaufärbung: Fast wie im Brustmark.

Nach van Gieson: Glia in der weissen Substanz inselförmig gewuchert. Corpora amylacea. Es giebt Ganglienzellen, bei welchen an seiner Ansatzstelle der Spitzenfortsatz wie unterbrochen wird durch eine helle Zone.

Nach van Gieson: Wie in der vorderen Centralwindung. Hier und da kleine Blutungen.

Fissura calcarina: Mit Toludinbla afärbung: Wio in der 3. Stirnwindung.

Nach Weigert-Pal: Die Veränderungen wie in der vorderen Centralwindung, aber schwächer.

Nach Bielschowsky: Die extracellulären Fibrillen sind in der 1. bis 
3. Schicht starl vermindert. Die Veränderung der Ganglienzellen wie in der vorderen Centralwindung.

Nach van Gieson: Wie in der hinteren Centralwindung.

\section{Rückenmark.}

Mit Toluidinblaufärbung: Im Halsmark sind die Ganglienzellen im Allgemeinen vermindert, zeigen Pigmentdegeneration und Chromatolyse.

Nach van Gieson: Die Ganglienzellen haben an Zahl stark abgenommen. Die Glia ist in den Hinter- und Seitensträngen inselförmig gewuchert.

Nach Weigert-Pal: Die Markfasern sind in den Hintersträngen unregelmässig, in den peripherischen Theilen der Seitenstränge etwas gelichtet.

Nach Marchi wie im Halsmark.

\section{Fall 9.}

J. L., 45 Jahre, Köchin, wurde am 18. October 1905 aufgenommen, war am 24. April 1906 gestorben.

Heredität. Als Kind Masern, sonst immer gesund. In der Schule gut gelernt, stets sehr heiteren Temperaments. Mit 16 Jahren crste Menses, regelmässig, ohne Beschwerde. Früher bleichsüchtig. Hat eigentlich immer bleich ausgesehen. Nach der Schule in Stellung, dann Köchin. Seit 5-6 Jahren selbstständige Köchin. Mutter gestorben an Gelenkrheumatismus, 64 Jahre, Vater gestorben an Lungenblutung, ca. 61 Jahre. 1893 Magenbluten, lejcht. Seit 15. Angust vergnügt und heiter, aber etwas matt und elend, klagte ïber Druck im Nacken und Kopf, Sehmerzen in den Augenhöhlen, Ohrensausen. Im September heftiger Brechdurehfall, der sie sehr sohwächte, ging aber nach einigen Tagen vorüber.

8. September auf einer Hochzeit sehr vergnügt, lachte auffallend viel, redete viel über dasselbe; 2 Tage nachher lachte sie noch viel. Dann wurde sie still, in sich gekebrt. 13. September Abends beim Abendbrot griff sie sich plötzlich mit der Hand an den Kopf: „0, mein Kopf, mein Kopf, ich krann nicht mehr denken, wenn ich doch bloss nicht wahnsinnig werde". Dann jammerte sie, sie habe keine Wohnung, müsste auf der Strasse liegen, müsste verhungern und erfrieren. Wurde zu Bett gebracht. Am andern Morgen wieder klar: Arzt wurde geholt, verordnete Medicin. 14.-15. September ganz klar, am Abend jammerte sie wieder. War ganz traurig. Könne nicht mehr leben, müsste sich ertränken. Anfangs wechselten diese Klagen mit völliger Klarheit, später blieben andauernd die Klagen. "Habe keine Sachen, keine Papiere, bin nirgends angemeldet; und das ist ein grosses Verbrechen. Bin unglücklich und verloren, beknmme grosse Strafe, soll in's Gefängniss". Schlaf und Appetit schlecht. Stuhlgang regelmässig. Verhielt sich immer ruhig. Seit 2 Jahren Climacterium.

Status: 18. October wird sie von der Schwester gebracht. Geht rubig auf die Abtheilung. Graciler Knochenbau, mässig entwickelte Musculatur, 
geringer Ernährungszustand. Schädel auf Druck und Beklopfen nicht empfindlich. Keine Druckpunkte. Pupillen unter mittelweit, gleich rund.

$\mathrm{R} / \mathrm{L}+\mathrm{R} / \mathrm{C}+\mathrm{A}$. B. frei.

Zunge gerade, zittert nicht, stark belegt, Gebiss defect. Gaumen gleichmässig gehoben. Sprache ohne Störung. Leichter Tremor manuum. Quinquaud + . Keine Motilitätsstörung. Gelenlie frei. Mechanische Muskelerregbarkeit nicht erhöht. Leichtes vasomotorisches Nachröthen. Patellarreflexe sehrlebhaft. Patellarclonus nicht vorhanden. Achilles +. Kein Fussclonus. Zehen plantar. Gang sicher. Kein Romberg. Sensibilität ohne Störung. Lungen und Herz ohne Besonderheit. Puls 80, regelmässig, atwas klein. Urin ohne Eiweiss und Zucker. Zeitlich und örtlich orientirt. Aengstlicher, trauriger Stimmung, sitzt etwas starr mit ängstlichem Gesichtsausdruck da, antwortet nur mit leiser Stimme; sehr langsam in allen ihren Bewegungen.

22. October. Verbält sich ruhig. Aeussert spontan nichts. Sehr gedrückter Stimmung. lsst ziemlich gut.

26. October. Gegen Abend vorübergehend ängstlich. Sehr gedrückter Stimmung. Sprach spontan nichts.

28. October. Sehr ängstlich, fortwährend aus dem Bett. Nach Dauerbad etwas ruhiger. Isst wenig. Mittags mitunter Erbrechen.

3. November. Aengstlich. Jammert leise. Leib aufgetrieben, druckempfindlich, bis zum Nabel Dämpfung. Auf hohen Einlauf Stuhl. Auf Katheterisation $1 / 2$ Liter Urin.

7. November. Andauernd sehr gedrückter Stimmung. Aengstlicher Affect. Sitzt aufrecht im Bett. Drängt aus dem Bett. Starre Haltung. Auf Katheterisation $1150 \mathrm{com}$ Urin, Eiweiss in Spuren, keine Cylinder.

11. November. Immer noch ängstlich. Urinlassen erschwert. Isst in den letzten Tagen wenig.

25. November. Andauernd ängstlich, unruhig, lässt spontan Urin. Isst sehr wenig.

26. November. Spuckt heute Mittag alles ihr mit dem Löffel gereichte Essen auf die Erde. Sondenfütterung heute Mittag.

30. November. Ischuria paradoxa. Urin stark ammoniakalisch riechend, stark alkaliseh, enthält Spuren Albumen.

16. December. Liegt ruhig zu Bett, gedrückter Stimmung, spricht nicht. Nässt ein.

24. December. Erbricht seit 2 Tagen alles, was ihr mit der Sonde gereicht wird. Nährklystiere nicht gehalten.

29. December. Kochsalzinfusion.

11. Januar 1906. Auf Magenspülung wird Fütterung obne Erbrechen vertragen. Verhält sich völlig ruhig. Spricht nicht. Nässt häufig ein.

14. Januar. Abends Temperatur über $39^{\circ} \mathrm{C}$. ohne nachweisbaren Grund.

15. Januar. Heute fieberfrei. Erbricht die Fütternng trotz Magenspülung. Spricht nicht, liegt wie starr im Bett, macht kaum eine Bewegung, zeitweise unsauber. Untersuchung des erbrochenen Mageninhalts: Freie Salzsäure in Spuren. Gesammtacidität $0,03 \mathrm{pCt}$. Milchsäure 0. 
16. Februar. Antwortet auch auf Fragen fast immer mit „Nein". In den letzten Tagen Sondenfütterung nicht nöthig, trinlit die ihr gereichte Fütterung.

22. Februar. Etwas theilnehmender. Verweigert feste Nahrung, trinkt ihre Fütterung. Führt heute den Becher selbst an den Mund.

3. März. Isst allein wenig. Befolgt einzelne Aufforderungen. Antwortet auf Fragen mit Ja oder Nein.

6. März. Abends traurig, ängstlich, weint, es seien schwarze Männer da.

12. März. Weint öfters. Glaubt, Männer zu sehen.

22. März. Morgens sebr laut. Injection. Nässt dauernd ein. Sehr unsauber. Abends $40^{\circ} \mathrm{C}$., Fieber, Durchfall. Innere Organe ohne Besonderheit. Weint und jammert viel.

24. März. Remittirendes Fieber ohne nachweisbaren Grund. Völlig ruhig. Spricht nicht. Isst sehr wenig.

27. März. Fieberfrei. Verfallenes Aussehen. Isst wenig. Beginnender Decubitus.

8. April. Elender, verfallener Ausdruck. Trinkt die Fütterung. Sehr unsauber.

12. April. In den letzten Tagen wieder Fieber.

13. April. Starker eitriger Ausfluss aus, dem rechten Ohr. Die Untersuchung ergiebt eine alte chronische Mittelohreiterung. Verfallenes Aussehen. Apathisch, somnolent.

23. April. Puls langsam, irregulär.

24. April. Temperatur $41^{\circ} \mathrm{C}$, Puls nicht fühlbar. Morgens 9 Uhr 30 Minuten Exitus letalis.

Section: Schädel ziemlich dick und schwer. Dura nicht gespannt. Im Sinus long. Wenig flüssiges Blut. Pia leicht getrübt, rechte Hemisphäre mehr als links. Gyri und Sulci ohne Besonderheit. Ependym im 4. Ventrikel granulirt. Kleines, stark getrübtes Herz. F'ensterung der herabgerückten Aortenklappen. Fettige Fleckung der Aortaintima. Geringe fibrinöse Pleuritis. Eitrige Bronchitis des. Unterlappens. Lungenödem. Völlig glatter Zungengrund. Atrophische Leber und Milz. Zahlreiche Blutungen dsr Blasenschleimhaut.

\section{Grosshirnrinde.}

Mit Toluidinblaufärbung. 3. Stirnwindung: Es giebt Pyramidenzellen, welche zwisohen gesunden Zellen sich ganz blass verfärbt haben, deren Kerne sich zu Stäbchen verjüngt haben oder welche wie Schatten umgewandelt sind, in deren Peripherie spärliche Nisslkörper liegen. Es giebt Ganglienzellen, welche die Fortsätze verloren haben und rundlich angeschwollen sind, deren Kern blasig aufgequolien ist, deren Kernkörperchen intensiv blau gefärbt ist. Man findet auch Pyramidenzellen, welche dunkelblau gefärbt, deren Fortsätze auf weitere Strecken verfolgbar sind.

Die kleinen und mittelgrossen Gefässe bieten in den intervasculären und perivasculären Räumen massenhaft rundzellige Infiltration. An der Gefässwand findet man rothgelbliches oder gelbgrünliches Pigment. Endothel- 
und Adventitiakerne sind theilweise stark gewuchert, besonders an den Capillaren, daher sieht es aus, als ob die Capillarlumina mit denselben ganz gefüllt seien. Stellenweise zeigen die Gefässe Verdickung. In der oberen Rindenschicht finden sich viel Stäbchenzellen. In der Pia kann man auch starke Infiltration constatiren, besonders auf der Grenze des Rindensaumes, wo die Pia mit dem Rindensaum verwachsen ist. Die Piagefässe sind auch stark infiltrirt, Endothel- und Adventitiakerne gewuchert. In der Gefässwand sind Plasmazellen gruppenweise vorhanden.

Nach Weigert-Pal: Die Tangentialfasern sind mittelstark vermindert, stellenweise sind sie perlschnurartig anfgequollen. In der 2., 3., 4. Schicht haben die supra- und interradiären Fasern bedeutend abgenommen, besonders die ersteren. Radiäre Fasern auch aufgequollen, ihr Rand ist zickzackförmig.

Nach Bielschowsky: Die extracelluären Fibrillen sind in der 1. Schicht stark vermindert, hier und da als kleine Stücke vorhanden. In der 2. bis 3. Schicht sind die Fibrillen auch stark vermindert, die radiären Fasern auch. Die Pyramidenzellen sind theilweise diffus dunkel gefärbt und lassen keinen Unterschied zwischen Zellleib und Kern erkennen; der Spitzenfortsatz zeigt an der Ansatzstelle punktförmige Fibrillen, auf weitere Strecken sind seine Fibrillen mit einander verbacken, manchmal geben einzelne Fibrillen ein klares Bild. Stellenweise giebt es Ganglienzellen, welche blass verfärbt und in denen nur die Kernkörperchen noch schwarz tingirt sind. Die Fibrillen des Zellleibs sind stark zerstört.

Zwischen den veränderten Ganglienzellen finden sich hier und da gesunde Zellen. Stellenweise haben die Pyramidenzellen die Fortsätze verloren, besonders sind die kleinen Pyramidenzellen schwarz gefärbt und meistens fortsatzlos. Es giebt Pyramidenzellen, welche blass verfärbt, in deren Zellleib zerfallene Fibrillen als körnige Masse zerstreut vorhanden sind, deren Kern verloren, deren Spitzenfortsatz an der Ansatzstelle abgetrennt ist, und wo sich auf weitere Strecken noch ein klares Fibrillenbild zeigt.

Nach van Gieson: Die Gefässe zeigen starke Infiltration. Die kileinen Rundzellen sind meist in den intervasculären Räumen stark angehäuft, nicht viel in der Umgebung der Gefässe. Im Vergleich zu den Gliakernen sind sie viel kleiner.

Vordere Centralwindung: Mit Toluidinblaufärbung: Die Pyramidenzellen haben fast alle Fortsätze verloren, sind rundlich oder oval umgestaltet. Der normale Bau der Zellschichtung in der Rinde ist ganz verwaschen. Theilweise giebt es Pyramidenzellen, welche stark angeschwollen, sehr blass verfärbt, mit feinen zerfallenen Massen gefüllt sind, deren Kerne nicht erkennbar sind. Theilweise ergeben die Pyramidenzellen bomogene Schwellung.

Die Beetz'schen Riesenzellen haben sich blass verfärbt und zeigen deutliche Chromatolyse. Veränderungen der Gefässe wie in der 3. Stirnwindung, aber noch hochgradiger. An der Gefässwand findet man massenhaft Plasmazellen. In der typischen Form, wie sie Vogt schon beschrieben hat, bieten sie einen centralen Hof dar; der Kern ist meist excentrisch; seine Form rund, oral 
und chromatinarm. Die Kernmembran ist scharf blau gefärbt. Das Protoplasma des Zellleibes blass röthlich gefärbt, nicht körnig.

Es giebt Plasmazellen, deren Centralhof netzartig ist oder blasse blauröthliche Klumpen zerstrent erkennen lässt. Manchmal erscheint das Chromatin des Kerns netzartig. Der helle Hof ist manchmal an einer Seite des Zellleibes oder um den Kern herum oder auf beiden Seiten des Kerns vorhanden. Deswegen zoigt der Kern Halbmondform, ähnlich wie die Malariaplasmodien. Stellenweise sind die Capillaren verdickt. Markzellen an der Gefässwand.

Nach Weigert-Pal: Die Markfasern in der ersten Schicht stark vermindert, stellenweise perlschnurartig oder spindelförmig angeschwollen. Die supra- oder interradiären Fasern auch stark vermindert, die Radii auch.

Nach Bielschowsky: Die Fibrillen sind in der ersten Schicht klein zerfallen und etwas vermindert. Die grossen Pyramidenzellen haben stellenweise ihre Fortsätze verloren und sich stark schwarz gefärbt, stellenweise verjüngt. Die kleinen Pyramidenzellen haten Spitzenfortsatz, welcher manchmal schräg verläuft und sind stark schwarz tingirt.

Es giebt grosse Pyramidenzellen, welche sich rundlich umgestaltet haben, in deren Zellleib die Fibrillen in kleine schwarze Massen umgewandelt sind, deren Spitzenfortsatz verschmälert ist, während die Fibrillen des Fortsatzes noch klar erkennbar bleiben. Die Beetz'schen Riesenzellen sind meist gut erhalten.

Nach van Gieson: Wie in der 3. Stirnwindung.

Hintere Centralwindung. Mit Toluidinblaufärbung: Die Ganglienzellen zeigen stellenweise atrophische Veränderung, stellenweise homogene Schwellung. Die Gefässveränderung wie in der vorderen Centralwindung, aber etwas schwäoher.

Nach Weigert-Pal: Die Fasern in der ersten Schicht sind stellenweise stark vermindert. Sonst die Veränderungen wie in der 3. Stirnwindung.

Nach Bielscbowsky: Die Fibrillen sind in der ersten Sohicht stellenweise stark, stellenweise klein zerfallen und wenig vermindert. Die kleinen Pyramidenzellen baben langen Fortsatz und sind schwarz gefärbt. Die Fibrillen der Spitzenfortsätze sind an der Ansatzstelle körnjg umgewandelt, anf weitere Strecken dann miteinander verbacken. Die grossen Pyramidenzellen haben stellenweise die Fortsätze verloren und sich umgestaltet. Die Fibrillen des Zellleibes sind klumpig zerbrochen und die Kernmembran intensiv schwarz gefärbt. Es giebt Ganglienzellen, welche schwarz gefärbt sind, deren Spitzenfortsatz an der Ansatzstelle total abgetrennt ist.

Nach van Gieson: Wie in der 3. Stirnwindung.

Fissura calcarina. Mit Toluidinblaufärbung: Die Veränderungen der Ganglienzellen und der Gefässe wie in den Centralwindungen, aber schwächer. Mastzellen in der Gelässwand.

Nach Weigert-Pal: Die Tangentialfasern sind in kurze Stücke zerbrochen, mittelstark vermindert, die übrigen Fasern auch.

Nach Bielschowsky: Die extracellulären Fasern sind in der ersten Schicht mittelstark gelichtet, und die gröberen Fibrillen fast verschwunden. 
Die kleinen und grossen Pyramidenzellen sind stellenweise schwarz gefärbt, haben ibre Fortsätze verloren, und die Fibrillen des Zellleibes sind körnig zerfallen; aber sie sind meist gut erhalten.

Nach van Gieson: Hier und da sind die Capillaren verdickt, sonst wie in der hinteren Centralwindung.

\section{Rückenmark.}

Halsmark. Mit T'oluidinblaufärbung: Die Ganglienzellen zeigen im Vorderhorn stellenweise centrale Chromatolyse und Pigmentdegeneration. Die Capillaren sind gefüllt, die Endothelkerne gewuchert.

Nach van Gieson: Die Capillaren verdickt. Man findet Corpora amylacea.

Nach Weigert-Pal: Die Markfasern sind in dem binteren peripheriscben Theil der Seitenstränge gelichtet. Sonst keine bemerkenswerthe Veränderung.

Nach Marchi: Keine besondere Veränderng.

Brustmark. Mit Toluidinblaufärbung: Die Ganglienzellen der Clarke'schen Säule zeigen centrale Chromatolyse oder haben den Kern verloren und sich diffus blass verfärbt. Auch die Ganglienzellen im Vorderhorn sind mehr weniger verändert. Mastzellen an der Gefässwand. Ependymzellen gewuchert. änderung.

Nach Weigert-Pal: Die Markfasern zeigen keine besondere Ver-

Nach Marchi und van Gieson: Wie im Halsmark.

Lendenmark. Nach Toluidinblaufärbung, van Gieson und Marchi und Weigert-Pal: Wie im Brustmark.

Wenn ich die mikroskopischen Befunde der Fälle 1-8 kurz zusammenfasse, ergiebt sich folgendes Resultat: Die Fibrillen, sowohl die extracellulären, als die intracellulären, sind im Vergleich mit dem normalen Präparat in allen Gebieten der Hirnrinde entschieden vermindert. Selbst bei den Fällen, in denen die Fibrillen noch relativ gut erbalten sind, sind sie viel mehr in kleine Stücke zerbrochen, als normal. Auch in den Markfaserpräparaten scheint es, als ob ein allgemeiner Ausfall vorhanden wäre. Wo die Fibrillen stark abgenommen haben, sind die Markfasern meist stärker gelichtet, mit geringfügigen Ausnahmen. Die Ganglienzellen in der Hirnrinde zeigen atrophische Veränderung, homogene Schwellung, centrale Chromatolyse, selten Pigmentdegeneration und Vacuolenbildung. Besonders sind die Pyramidenzellen stärker verändert als die übrigen Ganglienzellen. Bei einigen Fällen sind die Ganglienzellen an Zahl bedeutend vermindert; die Gestalt der Zellen umgewandelt und die Fortsätze abgehackt oder ganz verschwunden. Aber im Allgemeinen ist die äussere Form der Ganglienzellen gut erhalten, 
während der Kern, die intracellulären Fibrillen und die chromatische Substanz deutliche Veränderung darbieten.

Beim Fibrillenpräparat zeigen die Fibrillen in den Fortsätzen meist ein klares Bild, obgleich sie manchmal miteinander verbacken oder verklebt sind zu dicken schwarzen Fasern, während die Fibrillen des Zellleibes in kleine Stücke zerfallen sind, manchmal mehrere kleine helle Stellen enthalten. Die Ganglienzellen des Rückenmarks, besonders in der Clarke, 'schen Säule von Brust- und Lendenmark, stellen meist centrale Chromatolyse oder Pigmentdegeneration und Atrophie dar, sind sogar manchmal an Zahl bedeutend vermindert, bald auf einer Seite, bald auf beiden Seiten.

Die Ganglienzellen im Vorderhorn zeigen die gleiche Veränderungoder Vacuolenbildung. Beim Weigert-Pal'schen Präparat sind die Fasern, welche aus den hinteren Wurzeln gegen die Clarke'schen. Säulen einstrahlen, manchmal auf der einen Seite vermindert. Die Markfasern in der weissen Substanz ergeben nach Weigert-Pal, Marchi wesentliche Veränderung. Um die kleinen Gefässe und besonders um die Capillaren finden sich Rundzellen, welche nach Tolvidinblaufärbung oder van Gieson intensiv tingirt sind und fast stets die gleiche Grösse haben, deren Zellleib kaum sichtbar ist. Sie sind stark angehäuft, besonders um die Gefässe der Markleiste oder in der Grenzschicht zwischen dem Mark und der Rinde. Solche Rundzellen findet man auch spärlich in der Gefässwand. Stellenweise sind Endothel- und Adventitiakerne gewuchert. Pigment und Mastzellen an der Gefässwand. Manchmal kleine Gefässe und Capillaren verdickt und vermehrt. Nur bei dem einen Fall (9) zeigen die Gefässe in den inter- und perivasculären Räumen starke entzündliche Infiltration von Rundzellen. An der Gefässwand lassen sich daselbst gruppenweise oder vereinzelt. Plasmazellen constatiren. Viel Stäbchenzellen liegen in der Rinde, besonders in der obersten Schicht. In diesem einen Fall hatte auch die Pia rundzellige Infiltration ergeben und war stellenweise mit dem Rindensaum fest verwachsen. Auf die Frage, ob es sich bier wirklich um Katatonie gehandelt hat, wird weiter unten zurückgekommen.

Die Trabautzellen sind in allen Fällen in den pericellulären Räumenk angehäıft, manchmal in die Zellen eingedrungen. Die Gefässe sind im. Rückenmark hier und da vermehrt und verdickt.

Die Gliakerne sind manchmal in der grauen Substanz vermehrt. Die Gliawucherung in der weissen Substanz ist unerheblich. Die Fibrillen erscheinen in unseren Fällen durchweg vermindert, manchmal stärker in Stirnlappen, manchmal in den Centralwindungen, manchmal. im Occipitallappen. Vlan kann aber keine topographische Abgrenzung: 
treffen, an welchen StelJen die Veränderungen am stärksten seien. Ausserdem war zu constatiren, dass die Fibrillen vielfach in kleine Stücke zerfallen und nicht wie normal auf weitere Strecken zu verfolgen waren. Der Zerfall der Fibrillen erscheint in der 1.-3. Schicht besonders stark. Ich habe auch wie Bielschowsky und Brodmann bei den extracellulären Fibrillen die groben und feinen Fasern unterschieden. Dieselben Fasern waren immer in gleichem Grade gelichtet. Der Fibrillenschwund nahm von der Tangentialschicht nach den tieferen Schichten hin ab. Die radiären Fibrillen waren auch manchmal stark, manchmal schwach gelichtet.

In den Weigert-Pal'schen Präparaten scheint ein ähnliches Verhalten zu bestehen. Hinsichtlich der Stärke des Fasersehwundes war eine Abhängigkeit vom Alter der Kranken nicht zu erweisen. Dagegen schien die Krankheitsdauer von Einfluss zu sein. In unserem Fällen liess sich wenigstens constatiren, dass die Kranken, welche über 2-5 Jahre an der Katatonie gelitten haben, stärkeren Fasernschwund darboten (Fall 1, 3, 4 und 5), während eine Kranke, welche erst ungefähr einen Monat erkrankt sein sollte (Fall 7 ) keinen so bedeutenden Fasernausfall erfahren batte. Die Veränderungen der Ganglienzellen betrafen im Allgemeinen die Pyramidenzellen, sowohl die kleinen wie die grossen. Dagegen hatten die polymorphen Zellen wohl auch manchmal mehr oder weniger Veränderungen erlitten, indessen in Allgemeinen nicht so erheblich. Die Beetz'schen Zellen zeigten deutliche Veränderungen wie Chromatolyse oder homogene Schwellung.

Ferner zeigten sie im Fibrillenpräparat deutliche Vacuolenbildung oder mehrere kleine helle Stellen, welche durch den Zerfall der Fibrillen entstanden schienen. Sonst hatten im Fibrillenpräparat fast alle Pyramidenzellen eine scheinbar gut erhaltene äussere Form und nur in einigen wenigen Gebieten waren sie deutlich umgestaltet, hatten ibre Fortsätze zum Theil oder ganz verloren. Dann war der Zellkörper, besonders der Kern, dunkel gefärbt und die intracellulären Fibrillen schienen stark zerstört. Oefters fanden sich auch bei den anderen Pyramidenzellen ausser den Beetz'schen Riesenzellen im Zellleib mehrere kleine Löcher. Die Fibrillen der Fortsätze waren verklebt; aber sie boten doch ein relativ klares Bild dar.

Hier und da konnte ich auch constatiren, dass der Spitzenfortsatz an der Ansatzstelle im Zellkörper scharf abgetrennt, abgeschnitten erschien, was Bielschowsky und Brodmann schon bei progressiver Paralyse beschrieben haben. 
Bei Toluidinblaufärbung boten die Ganglienzellen, besonders die Pyramidenzellen, meist chronische Veränderungen dar. Im Fall 1, wo die Veränderung der Ganglienzellen schwach war, zeigte sich vorwiegend homogene Schwellung, Die Anordnung der Ganglienzellen war meist gut erhalten und ihre Zahl nicht vermindert. Nur im Fall 4 erschien die Schichtung in allen Gebieten verwaschen und ausserdem die Fortsätze der Zellen abgehackt oder verloren gegangen. Die Ganglienzellen waren hier an Zahl entschieden vermindert.

Beim Fall 3 konnte man nur in der vorderen und hinteren Centralwindung eine Verminderung der Ganglienzellen und Zertrümmerung ibrer Fortsätze bemerken. Auch im Fall 1 war vielleicht die Anordnung der Ganglienzellen in der vorderen Centralwindung verwaschen. Hinsichtlich der Veränderungen der Ganglienzellen war etwas Charakteristisches für Katatonie nicht zu erkennen. Die Veränderungen, welche hier beobachtet wurden, findet man bei anderen Psychosen, wie progressiver Paralyse, Dementia senilis u. s. w. wieder.

Auch der graduelle Unterschied der Veränderungen gab keinen sicheren Anhalt, um etwa eine Psychose von der anderen abzutrennen. Bei unseren Katatoniekranken erreichten allerdings die Zellveränderungen und der Faserschwund manchmal fast das Bild der progressiven Paralyse.

Zalplachta hat geglaubt, dass die Dementia praecox klinisch der Ausdruck eines toxisch oder toxisch-infectiösen Processes chronischer Natur sei, die besonders die Gehirnrinde in ihren tieferen Abschnitten ergreife und am stärksten in dem Frontallappen anftrete. Dieser Ansicht kann ich nach meiner Untersuchung nicht beipflichten. In meinen Präparaten war auf Grund der Zellveränderungen von einem solchen toxisch oder toxisch-infectiösen Processe nichts festzustellen. Vielmehr betrafen die chronischen Veränderungen der Zellen statt die tieferen Schichten mehr die Pyramidenzellen in der oberen Schicht. Ferner kann ich nicht auf Grund meiner Befunde sagen, dass der Frontallappen immer besonders stark afficirt worden sei.

Die Trabantzellen waren gewöhnlich deutlich vermehrt und in den pericellulären Räumen angehäuft oder manchmal in den Zellleib eingedrungen, wie die Abbildung 1 zeigt.

Betreffs der Gefässveränderungen gehen die Befunde der Autoren auseinander. Dreyfus hat beschrieben, dass die Gefässe etwas blutreich waren, ihre Wandungen nicht verdickt, die adventitiellen Lymphräume nicht erweitert. Vogt hat gesehen, dass die Adventitia zellarm war, das Pigment an der Gefässwand angehäuft, und in einem Falle die Gefässwand verdickt. Cramer hat betont, dass in seinem Fall die 
Gefässwand nicht sehr kernreich war, Endothelkerne schmal, die Gefüsse vereinzelt in der Markleiste verdickt.

In meinen Fällen sind die Gefässe, besonders die kleinen und die Capillaren meist mit Blut gefüllt, bauptsächlich lagen Rundzellen in den perivasculären Räumen. Diese Rundzellen hatten sich mit Hämatoxylin und Toluidinblau stark tingirt, ihr Protoplasma war kaum sichtbar. Ihre Grösse entspricht der von Gliakernen. Diese Rundzellen waren manchmal um mittelgrosse Gefässe so massenhaft vorhanden, sogar an der Gefässwand ziemlich viel angelagert, dass es fast aussah, als ob sie entzündlicher Natur seien, aus den Lymphocyten abstammten. Anfangs zweifelte ich denn auch, ob diese Zellen die Glia darstellten, weil die Gliakerne sonst. gewöhnlich in Reibe dem perivasculären Raum der Gefässe anliegen und bei Anhäufung meist eine Seite bevorzugen, seltener gleichmässig an beiden Seiten der Gefãsse oder gar, wie bei unseren Fällen, hart an der Gefässwand sich finden. Ich habe aber die Präparate der Fälle $1-8$ mit solchen von sicherer progressiver Paralyse, welche mit Toluidinblau oder van Gieson gefärbt waren, verglichen und einen deutlichen Unterschied gegen die Lymphocyten constatirt. Stellenweise waren die Capillaren vermehrt. Hier und da habe ich Wucherung von Endothel- und Adventitiakernen gefunden. Pigmentanhäufung habe ich auch an der Gefässwand constatirt, sonst schien es sich in einem Fall nur um eine kleine Blutung in die perivasculäre Lymphscheide oder in das Grundgewebe zu handeln. Dreyfus fand eine Verdickung der Gefässwand, ich habe in vier Fällen Verdickung der Gefässe constatirt. In zwei Fällen war das Alter 45-53 Jahre gewesen, daher ist es auch möglich, dass blosse Altersveränderungen vorlagen. In 2 anderen Fällen betrug das Alter dagegen 31 und 28 Jahre, sodass man von Altersveränderung nicht sprechen konnte. Auffallend war, dass sich die Rundzellen in den perivasculären Räumen statt auf einer Seite streckenweise auf beiden Seiten stark anbäuften, wie die Abbildung 2 zeigt, besonders um die Gefässe der Markleiste. Manchmal fanden sich wohl ähnliche Zellen auch in der Gefässwand, aber nur sehr spärlich. Bei progressiver Paralyse sind die Rundzellen gerade in der Gefässwand und in dem intervasculären Raum massenhaft abgelagert und zugleich sind Adventitia- und Endothelkerne stark gewuchert. In keinem Falle sieht man, dass in der Umgebung der Gefässe, in dem perivasculären Raum die stärkste Anbäufung der Rundzellen ist.' Der perivasculäre Raum stellt wohl nur ein Schrumpfungsproduct dar.

Bei Paralyse ist der Kern der Infiltrationszellen diffus stark tingirt und der Umfang bei gleicher Vergrösserung erheblich kleiner. Die Kerne der Rundzellen in meinen Fällen waren mehr chromatinarm; nur die 
weniger zerstreuten Körnchen des Kerns erschienen intensiv gefärbt. Die Grösse betrug fast das Doppelte, die Form war manchmal auch länglich oder oval. Auf Grund dieses Verhaltens muss ich die Rundzellen bei Katatonie als Gliakerne ansprechen. Dass in allen Fällen die Gliakerne um die Gefässe so stark gewuchert waren, ist allerdings auffallend, besonders in der tieferen Rindenschicht und der Markieiste. Aehnliche Gliawucherung habe ich übrigens auch bei der progressiven Paralyse beobachtet.

Ueber das Rückenmark haben Klippel und Shermitte histologische Studien angestellt. Diese Autoren fanden in der weissen Substanz bei 2 Fällen (29 jähriger und 35 jähriger Kranker) Veränderungen, welche an die der Tabes erinnerten, nämlich deutliche Entartung an den hinteren Wurzeln der Lumbalregion mit "vollständiger Zerstörung der Achsencylinder; in dem Hinterstrang derselben Gegend Sklerose der Gefässe und Degeneration der Goll'schen Stränge. Sie haben im cervicalen Theil auch Degenerationen an dem inneren Theil der Gollschen Stränge beschrieben. Ich habe mit verschiedenen Methoden das Rückenmark untersucht, aber ich habe an den Hinterwurzeln und Hintersträngen keine bemerkenswerthen Befunde beobachtet. Ich habe in der Peripherie der Hinterstränge, besonders in der Umgebang des Sept. post., und in der binteren peripherischen Zone der Seitenstränge leichte Veränderungen constatirt, doch kann man diese wohl als einen Degenerationsprocess bei Katatonie nicht auffassen. Die erwähnten Befunde erinnerten vielmehr an die bekannten Altersveränderungen; manchmal handelte es sich auch wohl um Kuustproducte bei den leichten peripherischen Leitungen der Fasern, welche daher rührten dass die betreffenden Stïcke zuerst lange in Formol-Lösung fixirt worden waren, ehe die Weigert-Pal'sche Methode zur Anwendung kam. Klinische Symptome einer Rückenmarksaffektion hatten in keinem Falle bestanden. Uebereinstimmend hat Dreyfus im Rückenmark bei Färbung nach Weigert-Pal keine Degeneration gesehen; insbesondere waren die Hinterstränge stets völlig inact.

Klippel und Lhermitte wollen in den Zellen der Vorderhörner des Rückenmarkes Atrophie und einen körnigen Zustand mit Pigmentirung des Zellprotoplasmas festgestellt haben.

Auch ich habe in den Vorderbörnern gelegentlich Atrophe, Chromatolyse, Vacuolenbildung, seltener Verminderung der Ganglienzellen beobachtet. Ferner ist es in meinen Fällen sebr auffallend, dass die Ganglienzellen in der Clarke'scben Säule immer im Brustmark und Lendenmark starke Zerstörungen zeigten wie auf Abbildung 3. Die Ganglienzellen boten meist centrale Chromatolyse, manchmal Atrophie 
und Pigmentdegeneration, nur in verschieden hohem Grade. Es gab Ganglienzellen, welche stark angeschwollen waren, in deren peripheriscliem Saum feine Granula lagen, während ihr Centrum fast ganz hell und der Kern länglich schmal an die Peripherie gerïckt war.

Das Kernkörperchen erschien dann intensiv gefärbt, und um den Kern fanden sich nur wenige gröbere Granula. Ausserdem sah ich Ganglienzellen, welche im Centrum ganz hell, in der Peripherie noch gut erbaltene Nisslkörper besassen und deren Kern unerkennbar war.

Andere Ganglienzellen waren fast rund angeschwollen; der Zellleib in grosser Ausdehnnng sehr blass; in einem Theil der Peripherie fanden sich noch klein zerfallene Granula, der Kern war verschwunden.

Ferner gab es Ganglienzellen, welche oval angeschwollen wie Schatten verfärbt, in der Peripherie spärliche, blass entfärbte kleine Granula hatten, deren Kern ganz verschwunden war.

Einzelne Ganglienzellen waren stark geschrumpft und in Stücke zerfallen, im Zelleib nur noch zerstreute feine Granula, während ihr Kern garnicht sichtbar war.

Ausserdem bemerkte man, dass die Ganglienzellen in beiden oder einer CIarke'schen Säule stark vermindert sind. Einmal habe ich an der Clarke'schen Säule im Lendenmark in einer Seite spärliche Exemplare veränderter Zellen constatirt, während in der anderen Seite viel mehr Zellen vorhanden, aber auch fast alle stark verändert waren. Manchmal sind die Fasern, welche von den hinteren Wurzeln in die Clarkeschen Särlen einstrahlen, deutlich vermindert. Veränderung der Ganglienzellen in der Clarke'schen Säule sind bisher bei verschiedenen Rückenmarkkrankheiten beschrieben worden. So sind bei der herediditären Ataxie die Zellen der Clarke'schen Säule, sowie die Kleinlimbahnen nebst den Hintersträngen des Rückenmarkes verändert. Ferner können sich solche Veränderungen bei der Strangdegeneration, bei amyotrophischer Lateralsclerose, bei Syringomyelie u. s. w. finden. Bei allen diesen Fällen existiren aber klinisch darauf $\mathrm{zu}$ beziehende Symptome. In meinen Krankengeschichten wird dagegen über derartige Erscheinungen während des Lebens nicht berichtet.

Nachträglich habe ich das Kleinhirn nach Bielschowsky'scher Methode untersucht. Die Purkinje'schen Zellen sind im Allgemeinen sammt Kern schwarz gefärbt, haben stellenweise ihre Fortsätze verlorei und abgehackt, sind stellenweise ausgefallen und haben zwischen einander weitere Lücken gezeigt. Einige Purkinje'sche Zellen boten im Zellleib Vacuolenbildung. Die Fibrillen, welche in der Molecularschicht quer verlaufen, sind stellenweise geschlängelt und vermindert, stellenweise gut erhalten. Die Fibrillen, welche um die Purkinje'sche 
Zellen ein Korbgeflecht bilden, sind hie und da in kleine Stücke zerfallen und gelicbtet.

Es fragt sich also, ob man die starke Zellveränderung der Clarkeschen Săulen als zufällig oder abhängig von der Katatonie ansprechen soll.

Wemn es sich um einen Zufalibefund handelt, so ist es sehr auffallend, dass die Veränderungen in allen Fällen hervortreten.

Nun haben wir öfters bei Katatonikern sonderbare Haltungen und Bewegungen, die ein geradezu uncoordinirtes Gepräge tragen. Es wäre vielleicht denkbar, dass diese Haltungs- und Bewegungsanomalien dureh eine Störung des Coordinationsapparates, zu welchem auch die Clarkeschen Säulen gehören, hervorgerufen wären.

Die Ganglienzellen in den Vorderhörnern sollen wach Klippel und Lhermitte anch zerstört sein. In meinen Fällen zeigten sie manchmal Vacuolenbildung and viel Pigmentanhäufung, und nur in 2 Fällen erschienen sie an Zahl stark vermindert. Wie diese Veränderung zu erklären ist, kann ich nicht sagen. Es ist kaum möglich hier überall die Ursache in der intercurrenten Erkrankung zu suchen, weiche den Tod herbeigeführt hatte.

Ausserdem fand sich vereinzelt in den Gefässen der grauen Substanz hyaline Thrombose, manchmal Verdickung der Gefässe.

Ich möchte noch mit besonderem Nachdruck im Fall 9 auf die Beziehungen zwischen dem klinischen und histologischen Befunde eingehen, weil dieser Fall ein grosses Interesse bietet. In diesem Fall hatte die Anamnese der Kranken ergeben, dass sie sich im Klimacterium befand, sehr lange über Druck im Nacken und Kopf, Schmerzen in Augenhöhle und Ohrensausen klagte. Danach traten Angst und Depression auf. Bei der Aufnahme waren die Pupillen untermittelweit, gleich rund and reagirten. Keine Sprachstörung. Gang sicher; kein Romberg. Patellarreflexe sehr gesteigert. Keine motorische und sensible Störung. Psychisch trat jetzt der heftige Negativismus in den Vordergrund. Erbrechen nach dem Essen. Sie ass nicht, sprach nicht, sass aufrecht im Bett oder drängte heraus. Manchmal war sie sehr unruhig. Stuhl und Urin waren angehalten. Sie weint öfters; glaubte Männer zu sehen.

Pathologisch-anatomisch fand sich schon makroskopisch der Schädel ziemlich dick und schwer, die Pia leicht getrübt; das Ependym im 4. Ventrikel stark granulirt.

Mikroskopiseh hatten die Fibrillen und Markfasern in allen Schichten der Hirnrinde stark abgenommen. Die Ganglienzellen zeigten verschiedene Veränderungen. Es waren viel Stäbchenzellen und Trabant- 
zellen vorhanden. Die Gefässe erschienen vermehrt und manchmal verdickt. Viel Pigment an der Gefüsswand. Endothel- und Adventitiakerne gewachert.

In der Gefässwand bestand starke Infiltration mit Lymphocyten, besonders in dem intervasculären Raum. Man sah in allen Gebieten der Hirurinde meist an der Gefüsswand angehäufte typische Plasmazellen, manchmal vereinzelt im Grundgewebe. $A b$ und $z u$ waren Mastzellen in der Gefässwand. Die Pia war manchmal mit dem Rindensaum stark verwachsen; dort fand sich besonders starke Ablagerung von Lymphocyten. Das Rückenmark zeigte aber keine deutliche Degeneration in der weissen Substanz; nur die Ganglienzelleu in der grauen Substanz boten mehr oder minder homogene Schwellung, Chromatolyse u.s.w.

Dieser Fall zeigte also klinisch bis Ende des Lebens das Bild der Katatonie, während sichere somatische Symptome für progressive Paralyse fehlten. Dagegen war der histologische Befund ganz der einer progressiven Paralyse. Es erscheint einstweilen richtiger anzunehmen, dass es sich um eine ungewöhnlich verlanfene progressive Paralyse gehandelt hat.

Alzheimer hat betont, dass die Plasmazellen bei progressiver Paralyse in keinem Fall fehlen, auch in den acuten Fällen nicht.

Vogt hat bei Katatonie keine Plasmazellen gefunden; wohl aber bei Delirium tremens, ldiotie, Epilepsie.

Ich habe in meinen übrigen Fällen von Katatonie ebenfalls keine Plasmazellen constatirt.

\section{Zusammenfassung.}

1. Bei Katatonie sind die Fibrillen in allen Gebieten der Grosshirnrinde vielfach in kleine Stücke zerfallen und haben entschieden abgenommen. Es lässt sich nicht sagen, dass eine Stelle rcgelmässig am stärksten verändert ist.

2. Die Veränderungen der Ganglienzellen sind nicht charakteristisch für die Krankheit, sondern finden sich ebenso auch bei anderen Psychosen.

3. Die Veränderungen der Gefässe sind olne Bedeutung. Dieselben sind manchmal vermehrt und verdickt; an der Gefässwand liegt mässig Pigment. Mastzellen in der Gefüsswand.

4. Die Gliakerne erscheinen um die Gefässe lebhaft gewuchert, besonders in der Markleiste. Die Trabantzellen sind um die Pyramidenzellen deutlich vermehrt.

5. Regelmässig fand sich in meinen Fällen eine auffallende Veränderung 
der Ganglienzellen in den Clarke schen Säulen. Auch die Zellen in den Vorderhömern boten mehr oder weniger deutliche Veränderungen dar.

Zum Schluss spreche ich Herrn Geheimrath Siemerling meinen herzlichen Dank für die freundliche Ueberlassung des Materials und Herrn Professor Raecke für die Durchsicht der Präparate aus.

\section{Literatur.}

1. Schmauss, Pathologie des Rückenmarks. 1901.

2. Klippel und Lhermite, Démence précoce. Anatomie Pathologique et Pathogénie. Ref. Jahresbericht f. Neurol. u. Psych. 1904.

3. Klippel, Anatomie pathologique et nature de la démence préoce. Ref, Jahresbericht f. Neurol. u. Psych, 1904.

4. Mo Conaghey, A protest against the Use of the Therm. The Journal of mental Science. Vol. LI. p. 380.

5. Mondjo, Contributo anatomico e clinico allo studio delle demenza precoce. Annali di Neurologia. 23 fasc. 1-2.

6. Olregia, A. et Autonin, A. A., Contribution à l'étude de l'anatomie pathologique de la démence précoce. Jahresbericht $f$. Neur. u. Psych. 1906.

7. Zalplachta, Jean, Contribution à l'etude anatomo-pathologique de la démence précoce. Revista stündelor medicale No. 70-80.

8. Klippel und Lhermite, Rückenmark bei Dementia praecox. Neurol. Centralbl. 1906. S. 705.

9. Weber, L. W., Ueber acute tödtlich verlaufende Psychosen. Monatsschr. f. P. und N. Bd. 16 .

10. Eisath-Hall, Ueber Gliaveränderung bei Dementia praecox. Allgemeine Zeitschr. f. Psych. 1907. Bd. 64. Heft 4. S. 691.

11. Griesinger, Pathologie u. Therapie der psychischen Krankheiten. 1892.

12. Vogt, R., Das Vorkommen von Plasmazellen in der menschlichen Hirnrinde, nebst einigen Beiträgen zur pathologischen Anatomie der Rindenerkrankungen. Monatsschr. f. P. und N. 1901. S. 211.

13. Meier, E., Die pathologische Anatomie der Psychosen. Orth-Festschrift.

14. Moschtschenko, Ueber pathologische Veränderung in der Grosshirnrinde bei Dementia secundaria. Ref. Neurol. Centralbl. 1899.

15. Dreyfus, Ueber Tod im katatatonischen Anfall bei alter Dementia praecox. Centralbl. f. Nervenheilk, und Psychiatrie. 1907. S. 451.

16. Binswanger und Siemerling, Lehrbuch der Psychiatrie. 1904.

17. Niss1, F., Histologische und histopathologisehe Arbeiten. 1904.

18. Flatan, Jacobsohn und Minor, Handbuch der pathologischen Anatomie des Nervensystems. 1904.

19. Kraepelin, Psychiatrie. 1899.

20. Bielschowsky und Brodmann, Zur feinen Histologie und Histopathologie der Grosshirnrinde mit besonderer Berücksichtignng der progressiven Paralyse. Journal für Psychologie und Neurologie. 1905. Heft 5. 